University at Buffalo School of Law

Digital Commons @ University at Buffalo School of Law

1996

\title{
Rights, Remembrance, and the Reconciliation of Difference
}

David M. Engel

University at Buffalo School of Law

Frank W. Munger

New York Law School

Follow this and additional works at: https://digitalcommons.law.buffalo.edu/journal_articles

Part of the Law Commons

\section{Recommended Citation}

David M. Engel \& Frank W. Munger, Rights, Remembrance, and the Reconciliation of Difference, 30 Law \& Soc'y Rev. 7 (1996).

Available at: https://digitalcommons.law.buffalo.edu/journal_articles/478

(C) 1996 Law and Society Association

\section{IN COPYRIGHT}

This Article is brought to you for free and open access by the Faculty Scholarship at Digital Commons @ University at Buffalo School of Law. It has been accepted for inclusion in Journal Articles by an authorized administrator of Digital Commons @ University at Buffalo School of Law. For more information, please contact lawscholar@buffalo.edu. 


\title{
Rights, Remembrance, and the Reconciliation of Difference
}

David M. Engel

Frank W. Munger

\begin{abstract}
Rights in American society present a paradox-critics increasingly assert that proliferation of rights is undermining Americans' sense of community, yet scholars continue to document Americans' reluctance to assert formal legal rights. We explore the meaning of rights in American society by describing the intersection between the evolving civil rights of a previously excluded minority, culminating in the Americans with Disabilities Act of 1990, and the personal histories of two individuals who might potentially invoke or benefit from such rights. Tracing the life stories of "Sara Lane" and "Jill Golding" from childhood through adolescence to adulthood and employment, we relate the everyday relevance or irrelevance of law to important elements of the reconstructed pastthe development of self-concept and of one's place in relation to the social mainstream. The article, which is part of a larger project involving a more broadly based interview sample of adults with disabilities, analyzes life stories to critique familiar assumptions about the perceived conflict between rights and social relationships and about the mobilization of law. It also offers an innovative approach to the study of law and legal consciousness by involving Sara Lane and Jill Golding in the analysis of successive drafts and by including their reactions to what the authors have written.
\end{abstract}

Our thanks, first and most importantly, to the two individuals whose stories are discussed at length in this article, "Sara Lane" and "Jill Golding," for generously sharing their thoughts and experiences with us and with those who may read this article. We are deeply grateful for their time, patience, and commitment to this project. Our thanks, too, to an outstanding group of students who have assisted us with this project since its inception: Dana Campbell, Shelley Chao, Sara Davis, Sara Faherty, Christine Farley, Johanna Oreskovic, Leslie Platt, Dana Schulman, and Denise Yates. We are grateful for helpful comments on earlier drafts of this article, received from friends and colleagues who attended our presentations at the 1995 Annual Meeting of the Law \& Society Association in Toronto, at a Faculty Forum of the SUNY Buffalo School of Law in the summer of 1995, and at the 1995 Annual Meeting of the Research Committee on the Sociology of Law in Tokyo. We thank other readers as well, in particular Markus Dubber, Fred Konefsky, John Grima, Murray Levine, and Jane Winn. Finally, we thank the five anonymous reviewers of the Law ES Society Review, whose comments were especially helpful. This study was supported by a grant from the Law and Social Sciences Program of the National Science Foundation (Grant SBR-9411919) and by the generous support of the Baldy Center for Law and Social Policy and the School of Law at SUNY Buffalo. An earlier related study of disability and employment was funded by the Fund for Research on Dispute Resolution. Address correspondence to David M. Engel or Frank W. Munger, School of Law, State University of New York at Buffalo, Buffalo, NY 14260.

Law \& Society Review, Volume 30, Number 1 (1996)

c) 1996 by The Law and Society Association. All rights reserved. 
ndividual life stories weave in and out of the fabric of public events and social history. Autobiographical narrations by ordinary people reflect the influence of political change, of cultural transformations-and, at times, of legal innovation. Yet the threads of individual lives also constitute this fabric: Through the choices and struggles of individuals in their everyday lives, events are channeled in particular directions and history is carried forward. The telling of life stories becomes part of this process. By drawing selectively on elements of the remembered past, the autobiographical narrators create an identity and a destiny for their protagonist.

In our study, we listen to the drama of life stories. The narrators are individuals whom society often relegates to the margins: people defined as "disabled" because they use wheelchairs instead of walking or because they process written or spoken words in atypical ways. As we listen to these remarkable narratives, we seek to discern and to understand the points at which they might intersect with the law, for the narrators live in an age when legal rights have been deployed to transform their lives and their social identities. We approach this task with no preconception: We may discover that the law has left no perceptible traces in these life stories. We listen and we discuss these issues with the narrators and among ourselves. We then take a somewhat unorthodox step by returning twice to the narrators and presenting them with our interpretation of the stories they have told us. We ask them what they make of our renderings of their lives. Are their images recognizable when reflected in our interpretive mirrors? Would they have shifted the emphasis from here to there, omitted this, or added that? As we share the task of interpretation with the individuals we interview, we also offer them a greater opportunity to challenge and reshape the very framework in which we present their life stories.

Our investigation grows out of a puzzle, an inconsistency in two views of law and civil society in late 20th-century America. One view asserts that we are in the midst of a rights explosion, that the discourse of rights and individual entitlement has metastasized throughout society and destroyed traditional commitments to community and to relationships framed in nonlegal terms:

[E]verything I "want" gets defined politically as a "right." Thus, for example, my desire, now a right, to have easy access to a pornography channel on cable television is conflated with my right to be safe from arrest or torture for my political views. Civil rights are trivialized in this process. Political ideals and private desires are blurred or collapsed. By extension, of 
course, there is no such thing as an authentically private sphere. (Elshtain 1995:41-42)

According to this view, Americans increasingly look to the legal system to protect their ever expanding concept of "rights." Their expectation level is unrealistically-and dangerously-high (Glendon 1991:14):1 they expect nothing less than "total justice" (Friedman 1985).2 Such, at least, is the claim of one group of commentators.

Another group of writers, however, presents a different view of late 20th-century American society. These writers say that Americans seldom turn to the law and do so with strong misgivings (e.g., Galanter 1983; Trubek et al. 1983). They assert that Americans usually deal with legal problems by absorbing perceived wrongs without overt response. Americans seldom consult lawyers when they perceive themselves to be the victims of legal violations, and lawyers seldom bring lawsuits on behalf of those who consult them (Curran 1977). From this perspective, America is a nation of law-avoiders. Potential claims of right tend to be repressed, wrongdoers are often free to repeat their transgressions without fear of legal reprisal, and relatively powerless individuals suffer the consequences of an inability or unwillingness to invoke the law to protect their interests.

These two perspectives raise fundamental questions about the role of law in American society. Are the two views mutually inconsistent? One asserts that private lives and public institutions are ravaged by uncontrolled claims of right; the other depicts a society of passive victims reluctant to request the measure of protection to which the law entitles them, even when they suffer serious wrongs at the hands of others. Perhaps the two views are not inconsistent at all. Perhaps the first refers to a way of thinking and talking about law and society, ${ }^{3}$ while the second refers to actual behavior. But this, too, would be puzzling: Why should

1 Writes Glendon (p. 14): "Our rights talk, in its absoluteness, promotes unrealistic expectations, heightens social conflict, and inhibits dialogue that might lead toward consensus, accommodation, or at least the discovery of common ground. In its silence concerning responsibilities, it seems to condone acceptance of the benefits of living in a democratic social welfare state, without accepting the corresponding personal and civic obligations. In its relentless individualism, it fosters a climate that is inhospitable to society's losers, and that systematically disadvantages caretakers and dependents, young and old. In its neglect of civil society, it undermines the principal seedbeds of civic and personal virtue."

2 Friedman's (1985) study describes, but does not join, the outcry against heightened legal expectations among Americans (p. 150). Indeed, Friedmar criticizes those who falsify evidence to support their claim that we are in the midst of a litigation explosion. Nonetheless, his book does argue that American legal culture has evolved in the direction of "a general expectation of justice, and a general expectation of recompense for injuries and loss" (p. 5). He carefully distinguishes this heightened expectation from an increase in the frequency with which Americans use the law.

3 Glendon (1991), for example, focuses on the discourse of rights rather than the actual assertion of rights, but she does not place great emphasis on the distinction between talk and behavior. Examples of literature discussing rights talk include Tushnet 1984; Haskell 1987; Williams 1987; Milner 1989; and McCann 1994. 
Americans think and speak in terms of unrestrained rights assertion but refuse to seek legal enforcement when their rights are actually violated?

The paradox of rights talk and rights assertion has special significance for civil rights law in the late 20th century. Civil rights differ from other forms of legal entitlement. They concern themselves not only with the legal interests of those who belong to civil society but also with the issue of membership itself. Civil rights are rights of inclusion for the individual whom society otherwise excludes (Minow 1990). They go against the grain; they often violate social norms rather than institutionalizing them in legal form; they annoy, they outrage at the very moment when they most effectively insist on an identity and a legal status for the person who invokes them. When civil rights are not asserted, the consequences can be profound: invisibility, the erasure of the individual from the community's membership list. Yet it appears that civil rights are among the least invoked of all laws (Mayhew \& Reiss 1969; Curran 1977; Miller \& Sarat 1980-81). Even as the rights paradigm is extended from racial minorities and women to new groups defined by such factors as disability, sexual orientation, stigmatizing disease, or age, the actual use of civil rights laws by their intended beneficiaries remains highly problematic.

We are interested in the paradox of civil rights in American society. We want to know how these issues and debates play out in the lives of individuals caught in the crossfire between contending views. We ask how the declaration of new civil rights for historically marginalized groups actually affects their lives, and how individuals navigate between expanded opportunities for rights claims and the widely documented tendency of most individuals to shun the law when rights are violated. We listen to the words of individuals who are the potential beneficiaries of new civil rights legislation; we talk with them about their views, their experiences, their use or avoidance of the law, and their thoughts about the relevance of rights claims to their own lives and their hopes for the future.

\section{Life Stories, Legal Consciousness, and the ADA}

Few studies have attempted to trace the interconnections between a new law and the everyday lives of ordinary people who are its potential subjects. In our research, we try to understand the life stories and "legal consciousness" of a group of individuals during the time when a major civil rights law is being implemented, a law that might potentially transform their lives and their very identity within American society. We focus on the Americans with Disabilities Act of 1990 (ADA), in particular the provisions addressing the employment rights of persons with dis- 
abilities. We ask how this law interacts with the social and cultural processes that construct an identity for persons with disabilities and shape basic assumptions about their ability-and their right-to participate in mainstream social settings such as the American workplace. We present two illustrative life stories, drawn from a series of interviews with individuals in Western New York who have learning disabilities or use wheelchairs, individuals who could potentially invoke the ADA as they seek employment or on-the-job accommodations that would enable them to work.

\section{Enactment of the ADA}

Persons with disabilities are among our society's most numerous $\left(43,000,000\right.$ by congressional estimate $\left.{ }^{4}\right)$ and least understood minorities. Their social-and legal-history has been one of stigmatization, isolation, marginalization, dependency, and, in many instances, abuse, mistreatment, and unnecessary institutionalization.

The ADA represents Congress's most ambitious effort to protect the interests of persons with disabilities and to grant them full membership in American society. ${ }^{5}$ The statute aspires to eliminate the "major areas of discrimination faced day-to-day by people with disabilities" (sec. 2(b) (4)). This transformation of "day-to-day" life extends to the employment arena, where the statute prohibits discrimination in hiring and failure to provide "reasonable accommodations" to an otherwise qualified individual with a disability (sec. 102(b)). Reasonable accommodations include "making existing facilities ... readily accessible" and restructuring work and work schedules, acquiring or modifying equipment or devices, exam modifications, and providing readers or interpreters for employees with disabilities (sec. 101 (9)). The ADA mandates such accommodations as long as they do not impose "undue hardship" on an employer-that is, "significant difficulty or expense" in light of their nature and cost and the capacity of the employer to provide them (sec. 101 (10)). The

4 "The Congress finds that ... some 43,000,000 Americans have one or more physical or mental disabilities, and this number is increasing as the population as a whole is growing older" (ADA, § 2(a)). Zola (1993) observes that estimates vary from 25,000,000 to $60,000,000$. He questions all such estimates, because they perpetuate misconceptions of disabilities as "finite and static" and of people with disabilities as a separate and distinct minority group. Instead, he argues that evenyone belongs, or will at some time belong, to the group in question: "The empirical reality is that everyone, unless they experience sudden death, will in fact acquire one or more disabilities with all their consequences" ( $p$. xix).

5 Compare the Rehabilitation Act of 1973 and the Education for All Handicapped Children Act of 1975 (renamed the Individuals with Disabilities Education Act). The rapidly growing literature on the ADA and its likely effects on employment includes such studies as the following: Tucker 1989, 1992; Morin 1990; Feldblum 1991; West 1991; Gostin \& Beyer 1993; Blanck 1994; and Gooding 1994. For a selected bibliography on employment and the ADA, see generally Court \& O'Connor 1992. 
employment provisions of the ADA became effective in July 1992 for employers with 25 or more employees and in July 1994 for employers with 15 or more employees. The enforcement provisions of the ADA are the same as those Congress provided under earlier civil rights laws prohibiting discrimination on the basis of race or gender. ${ }^{6}$

\section{Law, Culture, and Consciousness}

The ADA articulates a bold aspiration to transform the social status of persons with disabilities, and it provides sweeping antidiscrimination measures and extensive accommodation requirements to achieve this aspiration. As much as any recent piece of federal legislation, the ADA represents an extension of the "rights paradigm" to new persons and social arenas. Yet there is a real question whether-and how-legislative enactments of this kind actually intersect with the "day-to-day" experiences of persons with disabilities (ADA, sec. 2(b) (4)). Research in the field of law and social science has consistently demonstrated that the announcement of new rights and standards by legislators and judges is seldom translated directly into the transformation of "day-to-day" life in the sense that the ADA seems to contemplate. This is not to say that such laws have no effect but rather that the relationship between law and actual life experiences is extraordinarily complex and merits close and careful study. We investigate the connection between the ADA and "day-to-day" life through the life stories of its intended beneficiaries.

We structure this article around the autobiographical narratives of two individuals with disabilities: Sara Lane and Jill Golding (these are pseudonyms). We therefore view civil rights in this study from an unusual perspective. We ask how legal innovations like the ADA become interwoven with the life histories and the legal consciousness of individuals who might assert new rights. In the larger study of which these two life stories are a part, we have recorded and interpreted nearly 60 autobiographical narratives, from a preliminary sample of 180 individuals surveyed by phone. The interviews include men and women at three life stages: high school seniors, young adults in their early 20 s, and persons in

6 The enforcement provision of the Americans with Disabilities Act incorporates the power, remedies, and procedures set forth under prior civil rights laws. 42 U.S.C. $\$ 12117$. These statutory provisions authorize persons alleging discrimination, the Equal Employment Opportunity Commission, and the Attorney General of the United States to invoke the administrative and judicial powers of the state and federal governments. While the EEOC and the Attomey General have the power to enforce the ADA, initiation of compliance is left largely to the employer and employee. Employees are expected to raise issues of accommodation. Further, the employee bears the burden of seeking intervention by the appropriate governmental agency or court if the employee believes that an employer has not complied with the act's provisions. 
mid-life. Both Sara Lane and Jill Golding fall into the third age group. ${ }^{7}$

Our thesis is twofold. First, we argue that research on rights, culture, and legal consciousness can be enriched by the study of autobiography. Prior studies of legal implementation, mobilization, and consciousness have tended to focus on a relatively narrow slice of time in which to discern the effects of new law. By contrast, we ask whether and how law becomes active over the course of a lifetime and to what extent particular legal changes (such as the ADA) become relevant to individuals as they progress through different experiences and life stages. Our broader autobiographical inquiry illuminates several aspects of individual life stories that help us to understand the relevance and irrelevance of law. Among these, we focus in particular on the shaping of individual identity from childhood to early adulthood; the significance and patterning of relationships with others; and the capacity of an individual to negotiate conflicts and seize opportunities in the life situations she or he confronts. We consider each of these aspects of individual life stories in our analysis of the autobiographies of Sara Lane and Jill Golding.

The second part of our thesis grows out of the first. We argue that viewing individual autobiographies over a broad sweep of time reveals the variety of ways in which rights can become active or remain inactive. Traditional studies of legal mobilization and legal implementation have assumed that, given sufficient knowledge and resources, individuals will choose to invoke the law whenever it would appear objectively to remedy a wrong or im-

7 What we call "life stories" or "autobiographical narratives" are accounts by Sara Lane and Jill Golding elicited through extended, loosely structured, open-ended interviews involving the two women and the two authors. After an initial telephone interview, we interviewed both of them in person three times; each in-person interview lasted about 90 to 150 minutes. All interviews were taped and later transcribed. Quotes and paraphrases included in this article are drawn directly from the transcripts, and omissions are marked by ellipses. Initial in-person interviews with Sara Lane and Jill Golding, like all initial interviews in our study, were structured by an interview outline designed to elicit detailed life stories and accounts of disability and employment. Interviewees were asked to describe childhood experiences related to family, school, and social interactions. They then traced their experiences through adolescence and young adulthood to the present. We encouraged them to describe the formation of ideas about self and relations with others and about the formation (and revision) of their expectations for the future. We asked about persons and experiences that influenced the development of such ideas and expectations and about educational influences from grade school through college. We also encouraged description of employment-related experiences. We asked whether and how the interviewees dealt with disagreements or conflicts, particularly if related to issues of accessibility, employment, or perceived unfairness in dealings with others. We did not mention "law" or "rights" until the final phase of the initial interview, leaving it to the interviewees to introduce their own views of law to the extent they themselves saw it as significant in their lives. Subsequent interviews with Sara Lane and Jill Golding were not structured by an interview outline but simply addressed questions arising out of preliminary drafts of this article, which we had shared with them. In the course of the second and third interviews, both women discussed these drafts, offered suggestions and alternative perspectives, and commented on the central themes we sought to develop. During the third interview, Sara Lane and Jill Golding met for the first time and put questions and comments directly to each other as well as to us. 
prove an unfair situation. Our interviewees did not think about law this way. For many of them, even in situations of extreme unfairness and disadvantage, the provisions of the ADA were largely irrelevant to their lives. In many instances, the law simply creates an inappropriate relationship to others, given the circumstances of individual lives and the ways in which men and women with disabilities have shaped their identities over time in relation to other people.

Yet we also argue that it is important to consider the variety of ways in which rights can become active in "day-to-day" life, even when individuals do not choose to assert them. Once again, we suggest, traditional studies of legal implementation and mobilization have adopted too narrow a perspective. Rights may be interwoven with individual lives and with particular social or cultural settings even when no formal claim is lodged. Rights can emerge in day-to-day talk among friends and co-workers; their very enactment can subtly shape the terms of discussion or the images and conceptual categories that are used in everyday life. Such subtle yet profound effects may be overlooked in traditional studies of legal impact, yet they can be detected through the analysis in depth of life stories.

We do not want to suggest, however, that our purpose is simply to measure the impact of law on everyday life. On the contrary, our study points to the mutuality and inseparability of law, culture, identity, and experience. Like Yngvesson (1988, 1993), we postulate a two-way process in which interchanges between the legal system and particular cultural settings "mutually shape" (ibid.) both the law and the social context within which it operates. Law is one of the elements that constitute the categories and routines of everyday life; yet, at the same time, these very categories and routines-and the individuals who participate in them-give form and meaning to the law (see also Harrington \& Yngvesson 1990).

"Legal consciousness" emerges from this continual interplay of law, everyday life, and individual experience. Recent studies of legal consciousness, such as Merry's (1990), have examined the ways in which people's ideas about law, justice, conflict, and fairness are continually tested against their experiences and are changed as a result. Ewick and Silbey (1992) define legal consciousness as a set of meanings that emerge out of social practices chosen by individuals from an "inventory" of practices available to them in a given cultural context:

[W] conceive of consciousness as part of a reciprocal process in which the meanings given by individuals to their world, and law and legal institutions as part of that world, become repeated, patterned and stabilized, and those institutionalized structures become part of the meaning systems employed by 
individuals. We understand consciousness to be formed within

and changed by social action. (Ibid., p. 741)

In this regard, we find helpful Bourdieu's (1977:77) concept of "regulated improvisation." Within a matrix of shared cultural meanings that are shaped, in part, by law, human actors "improvise": they act in creative and sometimes unexpected ways to construct consciousness, culture, and law itself. In this study, we explore the ways in which law, culture, consciousness, and individual action interact and "mutually shape" one another in the area of disability and employment after enactment of the ADA.

Our emphasis on life stories adds a new dimension to current studies of law, culture, and consciousness by emphasizing the emergence of identity and orientation toward law over the entire lifespan of the individuals we interview. We find that "legal consciousness" has roots stretching deep into childhood, adolescence, and early adulthood. The relevance of the ADA to the life and experiences of an individual with a disability depends on family relationships, schooling, and friendships (or isolation) beginning at a young age and continuing to the point where the individual is ready to begin work. Although we are not psychologists, we find that Jerome Bruner's (1990) description of "cultural psychology" has direct relevance for our research. Bruner and his associates have explored personal narratives of individuals and their families to capture the notion of a Self that emerges from experiences in a particular cultural context and is "distributed" among persons with whom the individual interacts. Social and cultural interactions produce a negotiated understanding of identity that is dependent both on the social environment and on the thoughts and actions of the individual. ${ }^{8}$ In this process of negotiating identity, Bruner cites the importance of religious and historical traditions, economic, social, and linguistic factorsand the law (ibid., p. 117).

We see Bruner's theory as consistent with our inquiry into how the identities of persons with disabilities are constituted in our society, what role law plays-or could play-in that process, and how such culturally constituted identities in turn determine the extent to which legal rights become active in the lives of persons with disabilities. ${ }^{9}$ We see identity, culture, and law as mutu-

8 "[A] cultural psychology imposes two closely related requirements on the study of the Self. One of them is that such studies must focus upon the meanings in terms of which Self is defined both by the individual and by the culture in which he or she participates. But this does not suffice if we are to understand how a 'Self' is negotiated, for Self is not simply the resultant of contemplative reflection. The second requirement, then, is to attend to the practices in which 'the meaning of Self' are achieved and put to use. These, in effect, provide us with a more 'distributed' view of Self" (Bruner 1990:116).

9 Other areas of psychological theory and research may also have some relevance, for example, attribution theory (see Graham 1991). However, we find Bruner's account of the development of cognitive structure over a lifetime most useful for understanding the problems we consider in this research. 
ally constitutive. Culture and law can shape concepts of Self; the Selves thus constituted can use (in a variety of ways) or avoid law as they continually negotiate their identities; and such use or avoidance of law in turn can redefine cultural categories and selfperceptions over time.

\section{Disability and Employment}

We are primarily interested in the employment provisions of the ADA. In American society, where independence and self-sufficiency are particularly prized, employment is a fundamental element of social identity. Status and social position are determined most importantly by the type of employment one holds (Blau \& Duncan 1967; Laumann 1970; Newman 1988). Supporting oneself by earning and spending money legitimates one's status as a full-fledged, adult member of the community. Conversely, people who do not work are doubly disadvantaged, not only by the absence of self-generated income but also by the moral stigma of dependency attached to any form of public support for those unable to work (Handler 1987-88; Oliver 1990).

We think it critically important, therefore, that the drafters of the ADA chose to apply the rights paradigm to the issue of employment for a group that has historically been excluded from ordinary jobs and career options. Yet the very concept of rights for persons with disabilities who suffer employment discrimination is itself a problematic idea. As Funk (1987:7) has observed: "The general public does not associate the word 'discrimination' with the segregation and exclusion of disabled people.... [T] he absence of the disabled coworkers is simply considered confirmation of the obvious fact that disabled people can't work." For centuries, social stereotypes and distortions have contributed to the popular misimpression that disability and employment are mutually exclusive categories. An extensive research literature examines the cultural images associated with disability and their effects on individual identity (e.g., Goffman 1963; Gliedman \& Roth 1980; Livneh 1983; Scheer 1984; Wright 1983; Groce 1985; Murphy 1987; Fine \& Asch 1988; West 1993). ${ }^{10}$

10 These social images undoubtedly condition the perceptions of some employers when they deal with job applicants who have disabilities. It should not be assumed, however, that such images are internalized by persons with disabilities or dominate their interactions with nondisabled persons. Fine and Asch (1988:11) criticize the frequent conclusion that the negative consequences of disability are "central to the disabled person's selfconcept, self-definition, social comparisons and reference groups." They note that such conclusions have rarely been reached on the basis of statements made by disabled persons themselves. "Because disability is clearly salient for the nondisabled," they argue, "it is assumed that the marked person incorporates the mark as central to a self-definition." Yet our research, and that of other scholars, shows that people with disabilities often develop skill in presenting themselves to others in different ways and in managing their relationships with others rather than merely conforming to culturally conditioned expectations. By listening to autobiographical accounts, we can see that the experience of having a disability and the values held by people with disabilities may be quite different from 
Our own research examines the images and social practices associated with two quite different types of disability. In this article, we present the life stories of Sara Lane, who uses a wheelchair, and Jill Golding, who has a learning disability. From a sociological point of view, it is important not to treat "disability" as a homogeneous category. Different kinds of disabilities have very different effects on the lives-including the employment experiences-of those considered "disabled" and are associated with fundamentally different kinds of interactions with employers. The stories of Sara Lane and Jill Golding illustrate some of these differences.

\section{Two Life Stories}

From many fieldwork interviews, we select two individuals for discussion here: Sara Lane and Jill Golding. Although the two women represent the two disability groups in our study, we choose to discuss the life stories of Sara Lane and Jill Golding not because of their typicality, in any sense of that problematic word, but because these stories illustrate in particularly compelling ways the interplay between autobiography, legal rights, consciousness, and disability. The distinctive qualities of these stories are what we seek. Because they span a lifetime, they do not fit seamlessly into the categories or theories derived from prior studies of legal mobilization or legal consciousness but offer, instead, a richer, more complex understanding of the interplay of consciousness and society. In their very distinctiveness, these two life stories demonstrate the range of possibilities, the variety of ways in which law and culture intersect with choice and happenstance, creativity and luck. They point toward new ways of understanding the connections between rights and everyday life. ${ }^{11}$

the views of disability and the values held by others or accepted by the culture at large (compare Makas 1988; Frank 1988; Gerber 1994, 1995).

11 We have chosen in this article to discuss just two stories selected from over 60 indepth interviews we conducted. At this stage of our research, our understanding of the interplay over a lifetime between consciousness, rights, and disability is still rudimentary. Focusing on detailed examination of two cases has seemed to us to be an appropriate way to proceed for several reasons. First, as we shall demonstrate, these two life stories alone enrich existing explanations of rights by challenging the adequacy of the concepts and theories of prior studies of legal mobilization and legal consciousness and by laying a foundation for new theory. Further, our study examines the interpretations individuals give to experiences that have occurred over the course of a lifetime. Because we believe that such interpretations are the product of a complex, contingent, but as yet poorly understood process, our first step, undertaken here, is to consider the selection, emphasis, and characterization of elements of the remembered past in only two life stories. Recognizing that such interpretations are rendered still more complex and contingent by our participation in the process by which they are recalled, we have asked our interviewees to reflect on our analysis in a second and third interview. Our methods, chosen to help us understand life stories, draw on familiar traditions in the law and society field, including the use of case studies in qualitative sociology and anthropology and the use of interpretive methods to understand meaning and action. 
We listen as carefully as we can to the words spoken by Sara Lane and Jill Golding, to the ideas and emphases that are most prominent in their accounts. Our discussions do not begin with law or rights but with their self-descriptions, with memories of family and childhood, with the experiences that shaped their sense of self and their views of employment. Only at the end of the interviews do we ourselves raise questions about law and ask Sara and Jill to comment directly on the role of rights (actual or potential) in their careers.

Although we quote their words and conform as closely as we can to the narratives they themselves produce, what we present is inevitably an interpretation shaped by our own perspectives and preconceptions. We have taken these interpretations back to Sara Lane and Jill Golding and asked for their comments and criticisms. Thus, the following stories consist not only of our summaries of the initial interviews but also of the interviewees' interpolations and critiques of our own interpretive efforts (which are set in italic type preceded by and followed by the symbol $\sim$ ). Of course, these critiques are also interpretations. At different times, each of us may tell a different life story, shifting the emphasis, highlighting one factor rather than another, darkening or lightening the story, or drawing different conclusions. We continually shape the past, even as the remembered past continually shapes us - who we are and who we might become.

\section{Sara Lane}

Sara Lane is a newspaper editor and reporter who uses a wheelchair as a result of childhood polio. Her life story and her professional career suggest a complex interplay between legal influences and concerns and her commitment to the web of relationships - with co-workers, news sources, editors, and employers-that constitute her workplace. The law has influenced employment practices and workplace accessibility in ways that have advanced Sara Lane's career significantly, but direct encounters with the legal system have also humiliated and degraded her. She doubts that she would invoke the ADA because of the potentially negative impact a disability rights claim might have on her own career. She would like to work more flexible hours and at home; but she would prefer to secure these arrangements as an employee and union member, not as a beneficiary of the ADA.

We first met Sara Lane at her desk in the bustling newsroom of the metropolitan newspaper where she now works. In this setting, everyone is visible to everyone else, and work areas are separated only by low partitions. During the interview, her colleagues worked and talked at adjacent desks; later the transcriber had difficulty distinguishing our voices over the noise of nearby con- 
versations. This workplace is the hub of Sara Lane's professional life. It is not a place for those who crave privacy and quiet. Reporters and editors are crowded together; there is constant noise and movement; the work and talk of one employee impinges on others; all can see and hear the activities of their co-workers; there is continual interaction and cooperation among employees. It was immediately apparent that Sara Lane had chosen a professional environment different from that of many other participants in our study. We sought to understand how this choice had occurred.

Sara Lane contracted polio before her first birthday. Her memories of childhood include many summers of operations and convalescence. Nevertheless, her parents-especially her mother, who later became a special education teacher-attempted to place Sara in "mainstream" settings throughout her childhood. Sara recalls meeting other children with comparable disabilities who led far more sheltered lives. These children, she now realizes, were destined for segregated and dependent adult careers. By contrast, Sara's family always expected her to pursue an education and a career in fully integrated settings. They made few concessions to her disability: she remembers rough and tumble physical play with her siblings ("They'd try to trip my crutch ..."). She also remembers being urged by her doctor as well as her parents to use crutches rather than a wheelchair, to resist "giving up" the struggle to walk. Her home was never modified for accessibility. Sara crawled up the stairs to her room on the second floor and thought nothing of it.

Yes, I think because my disability was so integrated into our family as a community, it just made it obvious to me that that's how it would be in the rest of my life. I mean, my parents accepted it, and they worked around it, and they did what they needed to do; but they never made it into this monstrous deal, in terms of, oh, we can't do that because of Sara, or we'll leave Sara home. That was never an option. . . . I just know that, because I was treated as an equal, as a peer, that when I went to get a career, I went to college, those barriers didn't exist in my mindthat they're going to leave you out because you're disabled. ${ }^{12} \sim$

Sara Lane played with other children in the neighborhood. She participated in sleepovers. Although she attended segregated classes in first through fifth grades, in order to receive physical therapy available only to children in the special education program, Sara's mother had her transferred to a regular education program in junior and senior high school. She saw greater opportunities for Sara in the mainstream environments, and Sara was indeed a successful and popular student. In Sara

12 We remind you that such italicized passages are Sara Lane's or Jill Golding's responses to our interpretive efforts. 
Lane's recollections of her childhood, her mother plays a critical role by creating expectations and selecting social and educational settings where self-sufficiency and a "normal" identity were most likely to emerge. She prepared the schools for Sara's arrival by talking with teachers ahead of time. "They were ready for me," Sara recalls of her mother's behind-the-scenes activities, and her teachers did in fact prove to be very supportive.

During this time, however, Sara Lane does not recall talking openly with her parents-or with anyone else-about disability issues. She did not learn how to make her surroundings physically accessible or how to communicate with others about accommodations. It was not until she entered college that she saw how beneficial a truly accessible physical environment could be. Her college was more enlightened than most at that time and had removed many physical barriers on its campus and in its buildings. For the first time in her life, she was able to enter and use a library. While in college, Sara Lane met other active and independent students with disabilities. She became more conscious of disability as a social issue and learned strategies necessary to involve herself in mainstream social activities.

$\sim$ It was very paternalistic, though. . . They really kept you under their thumb. . . . We weren't really integrated into the university as such. We were more responsible for going to this place called the rehab center, where we would report in for activities and if we needed counseling or we needed this or we needed that. And then, outside of that, you would take classes. . . But we were really watched and overseen. Most of us tried to really back away from it toward the end of our college career. It was way too paternalistic. We weren't allowed to have that same kind of freeing experience most college kids go through. At first it was quite comforting, because for many of us it was the first time we had ever been away from home. I mean it was terrifying. Into the first year or so it felt very comforting, and then it was like, get out of here. Let me have my college experience. Let me make my mistakes and figure this out myself.

College was enlightening and liberating in many ways for Sara Lane, yet it was here that she first encountered the perception that her disability would actually limit her career. In her journalism major, she met professors who told her that no newspaper would hire her as a reporter because of her mobility restrictions. Instead, she should accept what she considered a less desirable desk job as a copyeditor. A well-known television journalist visited the college and told her to give up journalism entirely because of her disability. She rejected this advice and kept her expectations high.

Sara Lane's disability did affect her first job application, but in a positive rather than a negative way. The Ardmore Gazette is owned by the Gannett Company, which in 1973 was getting out 
in front on the issue of affirmative action. Sara says that both her gender and her disability were pluses for the newspaper. She recalls that the editor thought it was "cool" to have Sara there.

$\sim$ I heard that later down the line: they thought it was quite cool. But the day that I went in for that interview, what he liked was that I graduated with a prestigious program and I was homegrown. And it was later that I saw the wheelchair play into it. But then there's prejudice. I mean they'll hire you, but then they'll stick you at a desk and they won't let you really show what skills you have. They put you at a copy desk, and they say, write headlines for the rest of your life, and don't move, and don't even ask us to be a reporter. And it was women editors all the way through who would give me my breaks. It was never a male editor; it was always the women. Because you would befriend them and they would get to know you, then they would say, well, go write something.

The same pattern was to hold true in a hiring decision later at the Bayside Tribune, a California newspaper where she worked from 1981 to 1986. The Tribune was also owned by Gannett, and its editor advocated hiring qualified persons of color and women. Sara was his second employee with a physical disability, and, once again, she says that this was a positive factor. In both Ardmore and Bayside, rights appeared to have played a part in the decision to hire Sara Lane. Rights became active in the employment decision, not because they compelled action, but because a growing disability rights movement succeeded in transforming the consciousness of some employers and employees. This cultural shift placed a positive value on the inclusion of persons with disabilities.

Sara Lane's early career benefited from the women's and disability rights movements. She emphasizes that rights opened the door to employment but did not guarantee her advancement; she believes that from her first job at the Ardmore Gazette, her achievements were perceived as genuine. As she advanced at the Ardmore Gazette, she says, her relationship with the management of the paper continued to be good. In the matter of accommodations the newspaper was very cooperative and low key: "They just kind of made sure I had what I needed without making a point of that."

The newspaper's favorable disposition toward her disability made it easier to discuss accommodations. Here she drew on the skills she learned in college, and she guided her employer through the steps required to make her environment accessible:

I think when they interviewed me for the job, they pretty much said, "What do you need?". . . And I said, "Well, I have to have good entry and parking, and I need to get into a bathroom stall." "Well, what's the easiest and cheapest way we can do that?" they always say. And you have to know, you have to 
teach them. And in those days, what you would do would be to take the bathroom door, the stall door off, and drop a curtain. And that's what they did.

She notes that accommodation was relatively simple when the costs were small. The door on a bathroom stall, for example, was replaced with a curtain; and, she recalls ironically, when the newspaper renovated a few years later, the management benefited from her presence because they had to buy 60 desks but only 59 chairs. When costs were high, however, accommodations became more problematic. For example, when the newspaper moved her section to the second floor, they refused to provide an alternative to a dangerous freight elevator, which she could not operate without assistance.

Although Sara Lane initially worked as a copyeditor, she eventually achieved her goal of becoming a reporter. Her disability sometimes affected her reporting style, but it never became the insuperable obstacle her college professors had predicted:

I know that when I do an interview I have to maybe approach it a little differently from another reporter. And ... I have to judge them on an individual basis, whether or not I'll mention something about the disability to the person I'm interviewingtry to make them feel more comfortable. Sometimes I just try to weave it into the conversation later. 'Cause I feel some people send me language, where they want to know . . . I mean, I'm interviewing them, but they want to know about me. . . I've done a lot of face to face, and ... at some point you just kind of bring it back to yourself and try to address it . . . in order for the interview to go on, so they'll stop obsessing about it.

Her experience at the Ardmore Gazette established a pattern for employment elsewhere. She left the Ardmore area for a number of years and obtained jobs at two other newspapers in part because the editors who hired her thought her disability helped to establish a desirable identity for their papers. Her disability was one factor, but not the only factor, since she had accumulated considerable experience in positions of responsibility. Editors also valued her other qualities. She said that the Bayside editor particularly liked her funky sense of humor. Her growing network of friends and professional associates has provided her with another resource that is not related to her disability. Her career has been shaped uniquely, but by no means exclusively, by her disability.

On at least one occasion, an encounter with the legal system had far more destructive consequences. Shortly after beginning work on the night shift as an editor for the Bayside Tribune in California, Sara Lane was attacked and raped as she returned to her home in Berkeley. Her attacker was caught, tried, convicted, and sent to jail, but not until Sara had been subjected to a humiliating cross-examination by a defense attorney who repeatedly 
challenged her for not running or fighting off her attacker. During the cross-examination, he forced Sara to describe her disability before the jury again and again. The judge, on the other hand, fearing reversal on appeal, struggled to prevent the jury from seeing her in her wheelchair so that her disability could not be cited by the defense as having unfairly prejudiced the jury against the defendant. She remembers feeling more discrimination in the courtroom than she ever faced at a job or in any other setting. She was shamed and humiliated both as a rape victim and as a person with a disability. Her family also had problems dealing with her attack and failed to provide the support she expected.

The negative responses of the court and Sara Lane's family contrast with the practical and supportive responses of her employer and colleagues. They were concerned and protective and made immediate arrangements to restructure her schedule to avoid the risks associated with leaving work at night. Nevertheless, Sara Lane decided to leave the Bay Area and return to Ardmore several years later, just before her attacker's release from prison. The attack and its legal consequences caused severe dislocations in her life.

About two years after the assault, while still working for the Bayside Tribune, Sara developed a romantic relationship resulting in the birth of a child. The man was unwilling to marry and they separated. Single parenthood and the imminent release of her attacker convinced her to return to the Midwest, where family and friends might provide a more supportive network and enable her to pursue her career while raising her child. That network also provided a job contact at the Midwest Tribune, her current employer.

Her experience at the Midwest Tribune was initially quite different from her other jobs. When Sara Lane was hired, the Tribune seemed less attentive to her needs than had her prior employers, who had made diversity an explicit hiring goal. Although the newspaper is-and was-subject to state and federal laws that prohibit discrimination, it has only one other employee with physical disabilities and little experience with accessibility issues. The editor who hired her asked about accommodations she would need and provided a protected parking space. But the only accessible bathroom was not on her floor, and the newspaper refused to provide one until Sara's co-workers protested on her behalf. When the paper agreed, she notes, they said "'Okay, we'll do it, what do we have to do?' And then I went through the whole thing about the curtain." One of the problems she faced in dealing with accommodations at the Tribune was that she had expensive medical needs and, for a short time, difficulties with her supervisor as well. Although she acknowledges that she could have brought the accessibility issues to the paper's attention and 
fought for"them, she was reluctant to do so "because of all the other complicated factors." The law entitled her to negotiate with her employer, but, having no other source of income and a great many medical needs, she felt that her ability to negotiate was undercut by her dependence on her job and her problematic relationship with her immediate superior.

The passage of the Americans with Disabilities Act brought some significant changes to Sara Lane's status at the Tribune, but these changes occurred through the unilateral actions of her employers and not because Sara herself chose to invoke her rights under the act. At first, she recalls, the newspaper assumed that the ADA applied only to customers, not to employees. But when the paper realized, much later, that it also applied to employees, "Somebody actually said to me, 'We treated you terribly. And we'll now try to make up and try to do something.' Yeah, it really took that law to get them to realize it." She believes that the paper's attitude has improved since then, and some accommodations have been made for her. She attributes the change in part to the increased value they place on her work but also to the ADA, which, unlike earlier civil rights laws for persons with disabilities, "has more teeth in it." She is negotiating with the publisher for paid leave while she has carpal tunnel surgery, "and I'm sure after some give and take we'll work something out. But he's very, he's now become extremely accommodating."

Yet even in this period of post-ADA improvements, Sara Lane feels reluctant to ask for accommodations specified by the new law. Instead of invoking the ADA to obtain flexible hours and permission to work at home, she would prefer to wait until the newspaper guild, the union which represents all employees, makes such a demand on behalf of all of its members:

I would work more ... . with the guild, with our union, than I would ever work with a lawyer or whatever on ADA issues. I think that's less threatening to them.... As much as [the publisher] respects me and does for me what he says he can, you have to play the game, you have to be careful. And there is a point in my career where I don't want my disability to be out there that much. You know, so that by going through the guild it's the more proper way to do it.

Sara Lane's reluctance to invoke the ADA, even after her employer unilaterally acknowledged its significance, underscores the paradox of rights for persons with disabilities. Although she sometimes feels frustration and even anger because of inadequate accommodations, she sees risks in invoking legal rights that might remove barriers and improve her work. For her to invoke the ADA might have a negative effect on the professional identity she has created over a period of many years and might prevent her from advancing to a higher position at the newspaper. The invocation of rights might suggest dependence, not the 
independence they were intended to promote. This irony is particularly compelling in Sara Lane's case, because she is aware that the law has, at several key points in her life, played a critically important role in helping her to forge a career that conformed to the active self-image she has held since childhood. Yet the assertion of rights could also undermine that career by suggesting to others that her disability really does make her different, less capable, less independent. When it comes to issues of identity and rights, she observes, "You have to be careful."

At the end of the interview, we paused to reflect on a life story that simultaneously spoke of independence and of helpful interventions by others, of barriers impeding access and of accommodations that facilitated a successful career, of egalitarianism and paternalism, of laws and a legal culture that opened doors at important moments and of laws and a legal system that posed great professional risks and inflicted pain and humiliation. We asked Sara Lane to reflect on the complexity of the story she had told and the subtle and sometimes contradictory roles law had played in her life:

$Q:$ Is this a success story?

A: Is this a success story? It's too early to tell. I have a lot of physical problems right now in my body. Now that I'm 40 , it's breaking down. From the use of the wheelchair, from carpal tunnel. And, to be perfectly, honest, I don't know if I'll make it to retirement. If my body will allow me to work, what I'm hoping is that technology will allow me to start working from home. And maybe part-time editor, part-time writer.

Her dilemma puts her ambitions at risk. She would like to ask for a promotion, but her need for carpal tunnel surgery interferes with this plan. She does not think she can ask for a raise and then leave work to have surgery. If she decides to stay at home part time and take a pay cut, she may not have enough income to raise her daughter. But a pay cut is only part of the dilemma that working at home would pose. As she observed, "part of being a newspaper person is being here, and having faceto-face contact with the writers and news sources. And while someone from IBM can maybe work their program at home, the newspaper's an inherently different business."

The newsroom is indeed a microcosm of Sara Lane's career. It has been a source of sustaining relationships. To banish herself from it would cut her off from the roots of her professional work. The newsroom has also defined the meaning of her disability. Early in her career, it defined that disability-in some respects, at least-as an asset. Now, her disability may force her to work at home and rely on technology to maintain contact with her work. She understands that such a move threatens nothing less than the loss of her professional identity. 
Q. Where have you fallen short?

A. Where have I fallen ... I'm not running this newspaper, yet.

It's interesting to talk to you . . . and then to read it all together, because actually I don't think when you live this you pull all these things together. I didn't really think a lot about how my disability played out in terms of my career or how it maybe led me to the next level of the career. But seeing it in black and white made so much sense. I mean it put it in perspective for me, which I thought was kind of unusual, because when you're living it you don't really think about it.

I guess that I'm a pretty optimistic kind of person; and I guess when you're living a lot of this, it doesn't seem quite as easy or quite as happy as it sounds when you put it down and you look back on it years later. But I did feel prejudice in the newsroom, and I did feel often to be an outsider, and I did feel that I had to work a lot harder to prove myself on a daily basis. . . . And you did get very, very, very tired of it after awhile. When you're out in the real world and you take your kid to the mall and you find that everybody who walks past you stares at you, that really starts to get at you after awhile. And there were times in the newsroom where that kind of staring was going on, that you just didn't feel they took you seriously or that they really wanted your opinion. And there were times when I would really lose my temper. . . I I said to the editors, how long do I have to be here before we get beyond this point, before this is not an issue anymore? . . . Personally, it's been very degrading. . . . And the fact that they wouldn't give me a bathroom stall on my own floor for three or four years was just degrading beyond belief. It was infuriating; and you would just kind of go along for awhile and be a nice happy-go-lucky kid, but deep down it was really eating away at you. . . . I didn't feel that I could go to them one more time and say, I've got to have a bathroom stall on this floor, because you are perceived as a whiner. And you are perceived as someone, oh, well, we didn't realize you'd be so much trouble when we hired you. You're always thinking, what if somebody comes after me? You don't want to spoil it for them. You don't want them not hired because you're perceived as a whiner, because you want a bathroom on your floor. So there's always weighing heavy that the next generation of disabled employees are going to be screwed because they didn't like you.

The women at the Tribune have had a terrible time, and we do not have a lot of senior women officials there. We have a few more now but not enough. We all have our little crosses to bear, but being a woman and being disabled and being a single mother with special needs has been very difficult. The Tribune is definitely 19 th century in its thinking. So that's how I would change it [i.e., the telling of her life story]. I would darken it quite a bit. 


\section{Jill Golding}

For many adults with learning disabilities, concealment is a daily practice, and exposure-to employers, co-workers, and friends-is a constant threat. Their disability becomes the center of a secret life, vast and significant to them but hidden from those with whom they work or interact. Revelation of this secret life might lead to misunderstanding, to erroneous impressions that they are unintelligent, incompetent, limited, or dependent. They fear that it might also lead to rejection of a job application or termination of employment.

Jill Golding is an exception to this common pattern. Jill is quite willing to speak openly about her dyslexia; and when she speaks, she often invokes the language of rights and antidiscrimination law. Yet Jill Golding's forthright approach developed relatively recently. Her learning disability was not diagnosed until 1991, when she was in her mid-20s. The diagnosis came at a time when, through psychotherapy and self-reflection, she was gaining other insights into her identity and her upbringing. It coincided as well with an upsurge in social awareness of disability issues and new rights guarantees for persons with disabilities, particularly through implementation of the Americans with Disabilities Act. In the intersection of Jill's life history and evolving disability law, we may find the origins of a distinctive legal consciousness in which the ethic of caring is closely linked to the language of rights.

Jill Golding observed that social and legal norms have changed significantly in recent years. In the past, "nobody cared"; today, accessibility rights, particularly for persons with mobility impairments, are a commonplace: "And where did that all start? Well, it started with one person." Throughout the narration of her life story, she weaves together the themes of caring and of individual rights assertion. By asserting rights, she, as a nurse, can ensure that she will be able to care professionally for others; by asserting rights, she can ensure that others will care for her, although she was not always cared for as a child; by asserting rights, she can be sure that other children, including her own, will be treated in the future with the care that she was denied.

Jill Golding, now in her late 20 s, maintains a positive and hopeful outlook despite numerous painful experiences throughout her life. Her grade school years were, in her narration, marred by illness, abuse, and humiliation. As early as kindergarten, she was sexually abused by a teenage boy, and from her perspective as an adult, this experience led to extreme discomfort in the presence of all her male teachers. At the same time, an undiagnosed learning disability impeded her classroom work and left her constantly in fear of exposure and ridicule. After her fourth-grade teacher spanked her with a ruler for misspelling an 
easy word on the board, Jill became terrified of being asked to read or spell in front of the class. Recollections of sexual abuse and anxiety over her learning disability merge and overlap as she tells her story. She became depressed and bulimic; she feigned illness in order to escape from the classroom and from contact with male teachers. The school nurse's office became her refuge.

The school nurse offered care and comfort. At an early age, Jill experienced direct connections between childhood disability, illness, and the compassion of a professional nurse. The humiliation and fear she experienced in school-when translated into stomach aches, vomiting, or even "fevers" produced by running hot water on thermometers-gave her access to a substitute mother who comforted and praised her. It is not surprising that Jill would later choose nursing as a career for herself.

Jill's own mother was, in her telling, a more distant and less understanding figure, whose attitude toward most difficulties was the same: "You prayed about it and God would take care of it." Her parents were public-spirited people, strongly committed to helping neighbors with their problems; but Jill recalls that they were not attentive to their own children. Jill's mother was also a nurse. In this complex mother-daughter relationship, Jill followed the service ethic and the career that shaped her mother's public life, while simultaneously identifying her mother's indifference as an important source of the pain that led her as a child to the office of another nurse and another mother figure.

When Jill was 12, she assumed primary responsibility for her younger siblings. After school and through the night, it was up to her to feed them, change their diapers, and care for them in place of her parents. At the age of 12, she acted out the ethic of care-becoming a mother to her siblings even as she searched for someone who would be a mother to her.

Reading became increasingly problematic as Jill advanced into middle school. Told that she was a bad student, she became "mouthy" at times or else shy and withdrawn. Since no one ever recognized her disability, she received no special educational services or support. Even when help was offered-she recalls that a friend's father, who was himself a teacher in another school, was particularly generous in helping her with her schoolworkher feelings of gratitude were mixed with fear and anxiety:

I was still really scared. He was a guy, you know, and until I was diagnosed as dyslexic I still always, in the back of my mind, thought I was stupid. And I didn't want people to pick up on that, so I didn't always, I tried to avoid situations.

The signs of a learning disability were evident if anyone had taken the trouble to read them. Jill learned easily in courses that used a workbook but failed in courses where the teacher lectured. She could not write or think fast enough to keep up in the 
less structured classes and would find herself staring at a blank sheet of notepaper at the end of the hour.

In high school, I thought that I was just stupid. There was a blank, broad "NO" in my head that said, you're never going to be an A student. Now I realize that there's different degrees of everything. Dyslexia does not mean everything is upside down, backwards, or whatever. And there's different avenues of how to deal with it.

An important incident in the middle school helped to shape her career interest in children with disabilities. A small class of developmentally disabled students was bused to Jill's school, where they became the objects of curiosity and hostility. A friend told Jill to write a note to one boy in this class, saying "Fuck you." Without knowing the meaning of what she was writing, Jill did as she was told. The school suspended her for three days, and her mother made her apologize to the boy. Jill recalls her mother saying,

You had no right to write that note to that child. You gave that note to that child because you didn't think he'd understand it. Well, he's a human being, and he has feelings. And he is just as smart as the rest of us. He might have a different way of showing it or using it, but you do not abuse him because he's in a different program.

Jill's mother also made her write a report on children with disabilities.

In researching this report, Jill contacted the United Cerebral Palsy Association and became fascinated with pictures in brochures showing therapists working with young children. The incident and the report Jill had to write as a consequence made her decide that, as an adult, she wanted to work with children with disabilities. Through such a career she could not only expiate her feelings of guilt for mistreating her classmate but also channel her own generous and caring impulses into work that accorded with her mother's value system. In her teenage years, Jill expanded her commitment from her own siblings to sick and disabled children in a local hospital where she volunteered. The school nurse sponsored Jill's volunteer work at the hospital, which was also where her mother was employed. Early in her life, following an unusual incident in which she had betrayed the ethic of caring, Jill began to forge a career path that affirmed her mother's public values yet simultaneously allowed her to nurture sick and disabled children with whom she closely identified because of her own painful childhood.

Working in the hospital, Jill received praise and encouragement, unlike the humiliation and criticism she experienced in school. Doctors told her, 'You're going to be a good nurse, or you're going to be a good doctor, but you're going to stay in this 
field because you've got the heart, and you've got what it takes to be a good one." Upon graduation from high school, she resolved to study either nursing or physical therapy. She was accepted into a physical therapy program in college, but withdrew almost immediately when she learned that she would have to dissect cadavers. She married and worked as a hospital aide for a time, but the marriage proved ill-advised. Her husband abused her and refused to allow her to reenter college. Jill became depressed and her eating disorder worsened. Receiving little comfort from her husband or her family, she entered therapy.

Therapy, in Jill's narration, marked a turning point: "A lot of the truths that had been secrets for many years came out." She gained a perspective on her life that allowed her to understand the connections between her experiences growing up and her illness and depression. She also gained enough confidence to confront her parents, to insist that they, too, undergo therapy. She countered what she characterized as a repressed and religious ethos in her family ("If you pray about it, God will take care of it") with a more assertive, even legalistic approach: if her parents refused therapy, she threatened to have Social Services take away her younger siblings, who were also experiencing considerable distress growing up.

I was never brought up thinking that you could set goals and attain them. I don't know what really triggered that. Probably the biggest thing is my therapist. And then of course getting involved with [children with disabilities]. That certainly sets you up for seeing what they've accomplished. I mean you see these people doing amazing things. . . [Therapy] gave me the self-esteem and the confidence. At the same time, I met my [second] husband, and he's so supportive. I think that was the strongest turning point. I feel bad that not everybody had the opportunity to seek therapy. When I went into therapy, my whole family sort of said, "God, she's nuts, and don't share it with us and don't talk about us." Of course, that made me all the more willing to get right in there and tell them everything. . . . I remember my first session. I walked in, I sat down, and I said, "I'm not going to tell you anything. I'm not going to talk. You can ask me questions and I will answer, but I will not offer anything. I don't know what to say. ". And she is just a great therapist. She was a role model for me also. She was very assertive. My husband says I'm overassertive, too demanding in some sense, but I think we all have some degree of overdoing certain things. And I'd rather be overassertive and considered too demanding than be taken advantage of. But I feel bad that not everybody has had that opportunity. I think God gives us little paths. I'm not a horribly religious person like my family, but I do believe that He has a reason for everything, but you have to use those things to your advantage. You have to seek out why is He doing this? What is this going to lead me to? 
Jill divorced her first husband and returned to college. For several years she "floated" from one program to another, dissatisfied with her course of study and frustrated with her difficulty in reading. Eventually she realized that she had a learning problem and insisted on an evaluation. As she describes this period in her life, she explicitly connects the discovery of her learning disability with the discovery of a capacity to advocate her own interests: "It was only because I'm very demanding at this point in my life that I went on and demanded that someone find what was wrong.". Her narration also links the ethic of caring to the assertion of rights. Who should pay for the costly evaluation? Although Jill was then in her mid-20s, she told her parents it was their responsibility because, had they cared for her properly as a child, she would have been diagnosed at a much earlier age and her childhood would have been far less painful:

There's someone at [-Clinic] that will test me. Would you be interested in paying for it? I feel it's your responsibility, because this is something that should have been picked up on years ago, when I was in your care. So I think it's your responsibility.

$\sim$ I was determined. I wanted to find out what was wrong. And if I had to drive two hours, that was acceptable to me, because I wanted an answer. Some people don't want answers. Some people are not willing to go to that length simply because they don't either have the self-esteem or the income.

Armed with a professional evaluation of her learning disability for the first time in her career as a student, Jill returned to college. She received the accommodations recommended by the learning specialist, and her academic work improved significantly. She completed her nursing program and continued her work with children as a professional nurse. She loves her job, her health is improved, and she is happily remarried to an understanding and supportive husband.

Jill's discussion of employment rights for persons with learning disabilities reflects her own recent transformation. She is aware that her reading difficulties might affect some aspects of her work, such as preparing medications for the children. She arrives at work half an hour early to give herself time to go through the orders slowly and carefully. She is happy and comfortable in her present job but worries that she might encounter misunderstanding if she had to apply for work with a new employer. If an employer refused to hire her because of her learning disability, she describes her likely reaction in unusually legalistic terms: 
Oh, I would go to court and I would fight back, because that is not right. . . . They have to let me prove myself. If I proved incompetent, if I proved that I was giving meds in error or that my order was incorrect, if they have reason to not hire me, that's fine. But don't create a reason unless it's there. . . . They're saying that I can't do my job, and I can. And unless they show me just reason why I can't, or how this interferes with my job, then they can't discriminate.

Few of our interviewees with learning disabilities viewed their situation through such a rights-tinged lens. Her perspective is distinctive because it equates learning disabilities with physical disabilities ("If I had one arm, that is no different") and with the issue of racial discrimination ("It's as equal as black and white or minority versus majority"). To enforce such fundamental equality rights, Jill feels she must be "hardheaded" and "demanding," by which she means, "I would fight as much as I could."

Jill distinguishes, however, between discrimination in the hiring process and discrimination on the job. If her job application were rejected because of her disability, she would fight hard "to prove to them that they better not do it again"; but in the end she would probably not take the job. She would not want to work in a setting where her employer had doubts about her and hired her simply because the law required it. She would fight them so that their attitudes would begin to change, but she would seek work elsewhere.

Fighting for accommodations on the job is a different matter. Here, too, Jill would be tenacious, but there is no question of moving on to another job after winning a legal victory. Jill's reasoning is important and reflects the close connections in her mind between caring and rights claims. An employer should not, she insists, refuse to accommodate her disability on the grounds that she must follow the same routines as all the other nurses or be disqualified:

Oh, then I would fight back. ... I need you to work with me. You deal with the situation. I'm a nurse and, especially in this field, no situation is identical. Do I treat my patient like the patient in the next bed? No, every person is different. So don't tell me that there's anything concrete.

The analogy is revealing. Jill compares herself to a hospital patient, inverting the professional relationship in which she works every day (employer should be to Jill as Jill is to patient). By asserting her rights, she can guarantee that her employer will treat her with the same individualized care that she, as a nurse, provides her patients. Her patients, of course, are the beneficiaries of Jill's altruism and compassion, which has its origins in the failure of others to care for her when she was a child (Jill is to patient as school nurse was to her and as caring mother should be to child). Although she never received such care in her childhood, she 
now views caring as an entitlement-for employees as well as for children and hospital patients. The entitlement is protected by law: if she is not treated with respect for her individual differences and needs, then she will invoke antidiscrimination law to assert her interests. Jill's perceptions of employment rights are thus connected to her identity, past and present: as a child, as a "patient" who was cared for by the school nurse, and as a health care professional who now cares for others.

For Jill, then, rights claims can enforce the ethic of caring which is the core of her adult values and commitments. Although she is personally entitled to the benefits of disability law, she also sees its value for others. Because she now has a child, she must protect her employment rights for her child's sake. More broadly, however, Jill asks, "What about all the kids who don't have parents that either care or don't have avenues that are accessible or whatever? I have to really do my part." Again, her perspective is simultaneously self-referential and concerned with children growing up as she did, without understanding and support. By asserting her own employment rights, Jill can pave the way for children who might otherwise have to suffer all the difficulties she experienced. A rights claim is not just a matter of entitlement for Jill, or of financial security for her own child, but an act of caring for children who, like Jill as a child, are vulnerable, frightened, and in pain.

$\sim$ I wouldn't disagree with any of the interpretations. I do have to apologize. There was one part in there where you said that "she" was able to incorporate a theme throughout her thing; and I'm thinking, there have been so many times when people-well, my husband in particular-will say, you jump from topic to topic. And I know I was with that interview. Of course it is more evident when I am nervous or in a new situation. But that was the one thing, I interpreted that as being, well she rambled on and on and on. But I don't think it was meant that way, and I certainly don't think that someone reading it would interpret it that way. It's just my own insecurity. . . . So that was the only part that I laughed and thought, oh that's so cute. I wonder if anybody else sees it that way.

The interview was very good in that you were able to get me on track. You kept it in order, basically. You were able to say, okay, now, let's start here and let's work our way up; and I think that that's important in something like this. And you were able to get up to the employment part of it. And fortunately I was employed at the time. I don't think I would change anything. I think that my views are still the same, and I don't foresee them changing.

I think anybody reading this will get a sense of, first of all let's say that it was somebody with a learning disability, or anyone really, they can read this and say there's certainly people out there that have accomplished things, based on whatever their history is. You can accomplish things. And that no person is the same. Anybody reading it, either they're reading 
it so that they can get insight for themselves or for someone else, and they're going to get that. Or they're reading it so that they can get some hope for something, and I think that they're going to gain that, too. . . .

I was thinking about you probably a week ago, before you called [to schedule the follow-up interview], because I was at work and I was sitting for my Board, and something came in a paper that my boss got. And she came to me and she said, "Look at this." She says, "They're advertising for readers for the Board of RN exams. . . My opinion is that if they can't read they shouldn't be sitting there and asking people to read for them." And I just looked at her and I said, "Do you think that's really fair?" And she said, "Yes, I do." Now to a certain degree I would agree that if they can't read, how can they read orders or how can they read their meds. But I said, "You know, I have dyslexia, and there are some things that I have to stop and I have to ask myself, what does this say? I have to slow down so that I don't misread it or misspeak it. But you cannot generalize everyone and say, if you can't read you can't take the test, because that's not fair. . . ." This was the first she knew. I said, "You knew I had dyslexia." But she really, either she didn't know or she had forgotten. And she just looked at me. And I said, "I guess I work very well with it, don't I?" And she said, "I guess you do." And that was dropped. . . . I'm thinking, "Oh, God. She doesn't know. Is she going to fire me?" I mean, based on the fact that she just got done saying, if they can't read, don't take the test. I'm thinking, "I haven't taken my exam yet. Is she going to call and say, well, she can't read . . . ?" You have to remember that she's not the only one out there that thinks that way. What if somebody sitting on the board that decides who reads and who doesn't for this exam . . . ? So I decided, what do I have to lose. You've got to start somewhere. And if you approach it then, you deal with the consequences at that time. You can't live in fear.

\section{Interpretations}

In presenting the life stories of Sara Lane and Jill Golding, we inevitably interpreted what they told us and suggested its relevance for our own inquiry into the role of rights in everyday life. Indeed, the act of presenting such stories is inseparable from the act of interpretation. Sara and Jill commented on our efforts and, at times, contributed alternative interpretations of their own. What, then, is there to add in a section we are calling "Interpretations"? Here, we would like to suggest more explicitly some of the theoretical implications of these life stories. We focus in particular on the insights they provide concerning the problem of rights and rights consciousness in our society. We approach this problem through a discussion, first, of life stories and identity formation and, second, of the processes through which rights become active in everyday life. 


\section{The Importance of Life Stories}

Life stories provide an important new approach to research on culture, legal consciousness, and law. Previous studies have surveyed present attitudes or narrow slices of a person's life containing specific legally relevant events. We take a longer view. Our interviews elicit narratives of a wide range of past and present experiences that shape identity and legal consciousness, and that locate disability in the concept of self that emerges from recollections of childhood, adolescence, and early adulthood. By exploring the life story as a whole, we gain an understanding of the ways in which an individual with a disability learns to negotiate conflict and opportunity, to pursue one form of employment rather than another, and to orient herself in distinctive ways toward social relationships and toward law.

Three features of these life stories seem to be particularly important-identity, relationships to others, and the capacity to negotiate conflicts and opportunities. The life stories of Sara Lane and Jill Golding suggest that each of these three features of the remembered past has a potentially important bearing on orientation to rights and the law. We discuss each of them in turn, illustrating as we do so the importance of our life story approach.

Life stories are not objective history; they are a representation of past experience, of events that may have happened long ago. Our interest is in the narrative account itself, in the ways that individuals employ their past to explain who they are and to help give order to present actions. We recognize that the past is a resource people always carry with them, but one they can appropriate in different ways at different times. As we illustrate at the end of our discussion of autobiography, individuals continually edit and rewrite these narratives of past experience, not entirely self-consciously.

\section{Identity}

Jerome Bruner's concept of the self that emerges through the practices of a lifetime-the experience of action and interaction-fits well with central themes in the life stories of Sara Lane and Jill Golding. From earliest childhood, parents, peers and teachers played a role in shaping their identities. Through such relationships, Jill and Sara were exposed to the perceptions and judgments of others and began to develop a "distributed Self"a self that emerged from the contexts and persons with whom they interacted. The perceptions and judgments gave meaning to their disability as well as to other qualities, and created expectations concerning their capabilities and achievement. As we learn from Sara Lane and Jill Golding, these experiences are 
remembered long afterward and contribute in important ways to the sense each has of herself.

Both life stories suggest that the way in which other family members viewed and responded to their disabilities was particularly important. Sara Lane's parents, by not treating her differently, encouraged her to minimize her dependency on others. They even refused to make physical accommodations for Sara within their home and to this extent "ignored" her disability. In other ways, her parents made extraordinary efforts on her behalf: They facilitated her peer relations and prepared her teachers for her at school. Sara remembers their efforts in two different ways. On one hand, she remembers her anger after learning at college about the physical accommodations that her parents might have made for her. She feels in retrospect that her parents were misguided in their efforts to shape her sense of self by trying to make her independent of physical accommodations.

But Sara also remembers benefiting from the nurturing and support she received from her parents, and she credits them with her ability to achieve despite the limitations that might otherwise have been associated with her disability. Looking back now, she is sure her mother helped smooth the way for her by working extensively behind the scenes with her high school teachers. Her memories of high school are positive, and her identity, the one she offers spontaneously, is the identity of the honors student, the active participant in school organizations, and the teenager with friends and a social life. Similar themes-her outgoing personality, friendships, and energy-continue in the narrative of her later life, and we believe that this story has sustained her sense of self as integrated socially, as deserving of respect and regard.

Jill Golding, in telling her life story, refers often to the lack of caring and the pain caused by her parents during her childhood. Symptoms of her undiagnosed learning disability were ignored or, more likely, misunderstood by her parents and teachers. When she asked for help with problems, she was told by her extremely devout parents to seek an answer from God. Jill's anger with her parents and her demand for their support represents a very recent change of perspective. From early childhood until quite recently, Jill's undiagnosed learning disability was mistaken for stupidity, not only by her teachers and peers, uncontradicted by her parents, but by Jill herself. Her identity became what others perceived. The effects of this identity imposed on Jill were profound and long term. It did not occur to her as a child, adolescent, or young adult to demand more caring from her parents; it was beyond her understanding that she might assert rights under the law mandating special education (although she has since discovered some of her classmates received these educational services), and no one asserted such rights on her behalf. 
Her early sense of herself as a person who was not entitled to care is bound up in her relationships with her unsupportive family, peers, and teachers and the effect that these relationships had on her identity.

Even after therapy changed Jill's understanding of her relationships to others and gave her a new regard for herself, Jill Golding requires reassurance. Her outward assertion of her rights is in part a way of expressing but also of affirming this change in perspective. She still approaches her employment with the belief that it is she who must make many accommodations without troubling her employer. Like stories we heard from many others with a learning disability diagnosed later in life, the identity imposed by adults and peers, who interpreted childhood symptoms of learning disability as stupidity, immaturity, or stubbornness, remains a self-perception that must be resisted.

\section{Relationships to Others}

The stability and supportiveness derived from relationships to others forms a second significant element of these life stories. Relationships not only shape self-perceptions from early childhood but become a goal that affects later decisions about career and employment. Jill Golding's relationship to the school nurse assumes particular significance in her life story. The school nurse's office became a place of refuge from the negative experiences of school and personal life, the only place where she received the caring she desired. Though other factors certainly shaped her career as well, Jill Golding's story highlights her wish to provide care for others, culminating in her decision to become a nurse. In her mind, the commitment of health care professionals to patients provides a standard against which to measure other relationships. To explain her willingness to advocate equal treatment for herself notwithstanding her disability, she draws an analogy between a nurse's commitment to provide equal treatment to all patients despite their different needs and her moral and legal entitlement to receive equal treatment from an employer despite differences created by disability.

Significantly, childhood and adolescent memories of relationships do not have the same symbolic power in Sara Lane's narrative of her life. Sara Lane has had an abundance of supportive relationships: with her parents, who continue to provide support for her single parenting, with peers and colleagues, who provide both friendship and professional connections; and even with employers, who have liked her and appreciated her work. Unlike Jill, she was not influenced in her choice of career by experiences of rejection. In some ways, Sara's disability played quite the opposite role-as a source of connection. At college she was able to socialize with many others who had similar disabilities. 
This experience is unlike that of individuals with learning disabilities who are often isolated and seek to conceal their disability out of a fear that others will misunderstand its nature. While Sara has almost always been the only person with a physical disability at her place of employment, her first employers welcomed her in part because of her disability.

Sara's lifelong sense of connection affects her thoughts about accommodations in employment. In her current job, Sara Lane feels concern about her future. She is ambitious and seeks advancement, and at the same time she faces uncertainty because of her health and requires financial and other kinds of support from her employer. Her concern, however, unlike the concerns of many other interviewees, contains no suggestion of shame in revealing her disability or fear of rejection; rather it is practicalhow much will her employer pay for and still treat her as a "player" in the career game?

\section{Capability}

In our first interview with Sara Lane, we were particularly struck by her ability to negotiate with others to reach an accommodation of her physical disability. At college, she had learned about shaping her environment to her needs, and she was able to use her knowledge to help employers make relatively simple, but unfamiliar, modifications of bathrooms, working areas, or parking arrangements. In a similar spirit, she helped people she interviewed as a reporter to adjust to her disability by explaining it during an interview in an unselfconscious way. She skillfully negotiated more substantial accommodations with her current employer while still leaving open the door to career advancement.

Our second interview with Sara Lane provided further insight into her sense of personal capability. After reading our initial write-up of her life story, she commented on the emphasis we placed on the importance of this skill. She said that her sense of capability often contrasted sharply with the sense of dependence displayed by others who had similar disabilities, a contrast she first encountered as a child at a summer camp for children with disabilities. We had attributed her resourcefulness to her college program, which seemed to emphasize self-sufficiency, but she cited her parents' insistence that she must try to get along with few accommodations. She described their perspective as typical of families with children who had contracted polio in the 1940s and 1950s. Such families typically followed the advice of the medical profession to do without accommodations in order to force these children to become independent. Referring to her achievements and her independence, she described herself as a "typical type A childhood polio victim." Sara's sense of her capacity to take care of herself and her knowledge of how to modify her 
environment have made her an exceptionally effective negotiator on her own behalf.

We suspect that many persons with disabilities learn such skills in managing the doubts, resistance, or concerns of others. These skills are acquired through a wide variety of personal experiences at all stages of life, and range across many degrees and levels of aptitude. A sense of capability, and an ability to negotiate with others, we suspect, can greatly affect the ways persons with disabilities capitalize or fail to capitalize on opportunities throughout their lives, but in particular they affect the ability to negotiate barriers and to manage conflict. It is possible that feeling more capable may also make a person more ready to assert moral or legal claims. Sara Lane, however, seldom uses rights in her strategies for negotiation, and indeed, for reasons related to her image as a career journalist, she wishes now to employ means other than the ADA to seek accommodations. Jill Golding, on the other hand, uses the language of rights quite readily in her efforts to demand regard for her needs.

\section{Construction and Reconstruction of the Past}

We want to underscore our earlier point that stories about the past can be understood and presented in different ways. We have described the past as a resource that can be used to explain and to construct the present. We heard different constructions of the past at different points in some stories. During our second interviews with Sara Lane, Jill Golding, and others, after showing them our sketches based on the first interview, we also learned how their perceptions of the past can shift and change, not always entirely under their control.

Jill Golding's story described both negative and positive relationships with others. For most of her life, her story was dominated by relationships in which she was mistreated or rejected. If we had spoken to her several years ago, that would have been the only story. Since her therapy and her learning disability diagnosis, her view of the past has changed. Many of us have had the experience of feeling differently about a past event after the passage of time; few have had such a radical change of understanding as Jill. She has fundamentally reinterpreted the significance of the experiences in her past. Jill now speaks in a very affirmative way about herself, seeing continuity between the good experiences of the past and choices she has made about her career. She has reinterpreted her failure as a high school student, viewing it through the lens of her greater knowledge about her disability. She has spoken with high school classmates and discovered that they had learning disabilities and had been given added assistance through the school's resource room. She realizes that such assistance could have-and should have-been afforded 
her, and she sees herself not as a failure (as she did at times in the past), but as someone deserving of the special care required by the law.

Sara Lane commented extensively on our summary of her first interview. Our sketch of Sara, included in this article, uses the newsroom as a symbol of her successful integration into employment. The interview itself, and its location, demonstrated her capacity to manage her disability. After reflection she said if she were writing the sketch, she would "darken" the picture. She would change the tone by emphasizing her frustration at being forced to accept inferior professional assignments until sympathetic editors finally gave her a chance to take on real reporting assignments. She would also emphasize the genuine anger she felt while waiting for the Midwest Tribune to install an accessible bathroom and, even now, her impatience with the humiliating stares of strangers when she accompanies her young child to the mall. We think this reinterpretation is significant, but it is not the only important version. Her first, more upbeat, version is one from which she herself may derive satisfaction, because it emphasizes her enthusiasm, resourcefulness, and the impressive record of success she has achieved. The darker, more painful story is also valid, but more private, and it contains lessons about the costs she will pay as she rises higher in the newspaper world. Still other ways of remembering the past are possible, and we are just beginning to explore such nuanced differences and their interpretation.

Life stories tell us how the past is remembered and the future forecast. The past is more than an ever changing subjective construct for it also contains facts that could be confirmed by the recollections of family or friends or by other historical evidence. We have based our analysis on the assumption that most of what we hear is confirmable in this sense, and we have gone on to draw our own inferences from Jill and Sara's references to parental support or abuse as well as from relationships and events that they described but did not interpret. But we are also impressed by the fact that these stories can be rewritten, sometimes as we listen. Aspects of the stories that are central to the narrators' lives and to their orientation to law-identity, relationships, and sense of capability - can evolve with changes in time and circumstance. Indeed, it is the retelling and continual transformation of life stories that makes it possible for individuals to draw new lessons from the past and pursue new possibilities in the future.

\section{When Rights Become Active: Life Stories and the Law}

Through life stories, we learn about sense of self, relationships between self and others, and the individual's understanding of her own capabilities. Each of these elements of life stories 
evolves over time, influencing and shaping actions and expectations. In turn, these three autobiographical elements influence orientation to law. We are particularly interested in how life stories shed light on two issues central to the current debate over rights in American society: the perceived conflict between rights and community and the effect of civil rights legislation on everyday life.

\section{Rights and Relationships}

Because we listen to life stories, rather than truncated accounts of selected legally relevant events or present attitudes toward law, we can consider and explore connections between past and present, between experience and expectations for the future, which Sara Lane and Jill Golding could not have conveyed to us if we had asked them simply to describe their attitudes toward disability, employment, or law. Through broad-ranging autobiographical narratives they are able to tell us, and we are able to appreciate, how identity, relationships, and capabilities evolve and help situate the law in their experiences and their expectations for employment. We may contrast their orientations to law in the broadest terms: Sara Lane, positive, capable and outgoing, has learned that she seldom needs to assert rights or the law even though she has the necessary knowledge; Jill Golding, whose recollections of childhood and young adulthood are far more painful, views disability rights as a means of affirming supportive relationships missing from her earlier life.

But such broad contrasts between Sara and Jill are just a starting point for our analysis. After listening to the life stories of Sara Lane and Jill Golding, we perceive new ways in which law becomes active in the employment context. The experiences recounted in these life stories cannot be fitted easily into categories that other scholars have used to describe patterns of legal mobilization or legal consciousness. For example, sociolegal research has often treated rights and relationships as dichotomous alternatives. According to such analyses, the stronger the bonds of interpersonal relationships, the less likely it is that law will become active (Black 1976). The life stories of Sara Lane and Jill Golding present a more complex picture. Both women seek-in strikingly different ways - to forge relationships, both personal and professional. They place an extremely high value on the creation and preservation of relationships, and their work expresses this high value. Sara Lane's job places her at the center of a bustling newsroom and a web of contacts with reporters, editors, and interviewees; Jill Golding's job enables her to act out the ethic of caring for others, which is central to her life.

Throughout their lives, their disabilities have affected and sometimes placed at risk the relationships they value so highly. 
Although the effect is not always negative, at times their disabilities obstruct the creation of relationships and threaten their professional careers. When this happens, rights may offer a solution to the problem, a way of guaranteeing access to mainstream settings in which relationships are forged, including the workplace. The interplay of relationships and rights, however, poses a complex dilemma because invoking rights does not necessarily lead in straightforward fashion to the restoration of full citizenship in the community for people with disabilities who are the victims of discrimination. Invoking rights under the ADA begins with an assertion that the claimant is different from other workers, and the difference bestows an entitlement that others cannot claim (Minow 1990). The entitlement could profoundly change the identity of the claimant or the nature of the work itself. How can the employee with a disability make such a claim while still preserving normal relationships with employers and coworkers?

The narratives of Sara Lane and Jill Golding, and of others with whom we spoke, have profoundly changed our thinking about this dilemma of civil rights and inclusion and, more generally, about the tension between law and continuing relationships. Sara and Jill have attempted to resolve such difficulties in ways that defy simple either/or categorizations-choosing either rights or relationships. Over their lives they have learned and employed various means of coping with barriers and maintaining important relationships. The dilemma posed by rights and relationships is not the same for Jill as it is for Sara, but rather it is dependent on perspective, on context, and on the pursuit of particular personal and professional goals.

Rights may be understood as conflicting with connections to others, but, as we learned from Jill Golding, rights may also be viewed as reinforcing relationships. Jill approaches the dilemma with an unusual confidence that rights and relationships are mutually reinforcing, that "caring" and rights assertion are closely connected. She confronts her co-workers and her employer when their words or behavior involve discrimination against her or others who have disabilities. Even for Jill Golding, however, there are limits to the connections between rights and relationships: even she cannot envision working for an employer after successfully suing for employment discrimination.

For Sara Lane, the dilemma of rights and relationships has been less intense. Partly through circumstance and partly through her unique ability to manage others' responses to her disability, she has bypassed the dilemma of rights and relationships at many stages of her career. To obtain employment, Sara Lane had no need to assert rights, because her employers were already prepared to place a positive value on her disability. Further, without asserting rights, she relied on her professional skills and her ability to help others adjust to her disability as she over- 
came what might have been, for others, insurmountable physical barriers, dead-end job assignments, or the unique challenges of dealing with the public as a reporter with a disability. Sara's approach to employment and professional relationships derives from a perception rooted in early childhood: that her disability and her employment are compatible.

Changing circumstances in Sara Lane's life, however, have more recently challenged this perception of compatibility and have, in a broader sense, raised the possibility that rights and relationships might indeed come into conflict. Orthopedic problems arising from her childhood polio have required surgery and have suggested to her the need for additional accommodations including, perhaps, working at times from her home. Sara Lane is quite conscious of the sensitivity of her situation and the need to exercise caution in rights assertion if she is to advance to higher professional levels. She also worries that if she is too aggressive in claiming her rights under the ADA, the company could decide never to hire another employee with a disability. Here, again, her perception defies easy dichotomization, because it is linked not to fears about the security of her job or the continuing relationships it makes possible but to strategic concerns about public perceptions, career advancement, and the broader impact of invoking rights.

\section{The Effects of Rights in Everyday Life}

The life stories of Sara Lane and Jill Golding have also moved us increasingly beyond familiar thinking about how laws and rights are invoked or "mobilized" in everyday life. It is easy to slip into a simplistic view of legal mobilization: Rights are either invoked or not invoked, somebody gets sued or else a potential claim goes unrecognized or is abandoned. We see in these stories, however, that rights can become active in everyday life in many different ways-not just when an individual decides to sue or assert a claim explicitly. Nor does the failure to assert a claim mean that rights have been inactive in a given situation.

True, one could imagine social arenas in which the ADA or other civil rights law have no effect at all on everyday life or, conversely, where individuals bring the law fully to bear by involving courts and lawyers in the workplace and by forcing a change in employment practices. Yet, neither of these extreme situations was apparent in the life stories of any of our interviewees. Sara Lane and Jill Golding suggest other ways in which rights might become active in everyday life.

Over the course of their lives, rights were powerful silent partners, shaping experiences and opportunities even when Sara and Jill did not themselves turn to law. Sara Lane attended college and entered the job market as the disability rights move- 
ment reached its peak in the early 1970s. Five years earlier, the college she attended would not have had accessible dormitories or a program especially designed for persons with disabilities. Had Sara Lane gone on the job market a few years earlier, it is unlikely that Gannett would have thought it "cool" to hire someone with a physical disability. These changes in her educational and professional opportunities had significant legal underpinnings. The evolution of disability rights activism helped to transform the environments in which she sought to study and work.

Now that she is well along in her career, her current employer is not nearly so enthusiastic about employing persons with a disability, yet the law has continued at times to play a contextcreating role. For example, Sara tells how her current employer unilaterally initiated changes after realizing that the ADA applied to his own employees and not just to customers. Sara Lane did not assert a claim or take any steps to mobilize the employment provision of the ADA. The employer's unilateral implementation of the ADA led him to realize that he had treated her unfairly: he apologized and attempted to comply with the law's requirements.

Jill Golding's experience with the context-creating effect of the law is quite different but equally telling. She is younger than Sara, and during her childhood the Education for All Handicapped Children Act (now the Individuals with Disabilities Education Act) had taken effect and, as she discovered later, provided benefits for some of her classmates. Because Jill Golding's learning disability went undetected by parents and teachers, however, she received no benefit from the law. Even so, educational rights become active as Jill Golding retells her life story. Now she perceives herself not as a child who was an incompetent student but as a capable person who was deprived of the educational rights to which she was entitled. In her account, rights affirm her identity as a capable person. She takes pride in the professional success she has enjoyed despite the deprivation of rights she suffered as a child. When her educational rights were recognized in college, her capabilities and potential became clear.

Rights may also become active in day-to-day interactions when people refer to them to legitimate their position as they confront and make claims on others. When Jill Golding talks with co-workers and employers, she readily supports her position by referring to the rights of people with disabilities. She has never "invoked" rights in the sense of asserting a claim against her employer or a third party. But in daily talk of the kind that goes on in most workplaces, she challenges statements by others when they fail to recognize disability rights, and she insists that others in the workplace acknowledge the norms of the ADA when discussion turns to issues of disability. Jill Golding attempts to inscribe rights created by the $\mathrm{ADA}$ into everyday discourse, to change the thinking and speech of everyday life to conform to 
the ADA. This discursive use of rights differs from usual ideas about mobilizing law but is, we think, a profoundly significant mechanism through which law can play a part in the transformation of everyday life.

Even when individuals with disabilities remain silent, however, the ADA could still become active in everyday life in a less explicit and more diffuse way, by contributing to a change in the terminology and conceptual categories used to refer to individuals, disability, and work. This is a more broadly pervasive effect than the direct, context-creating examples discussed earlier. In those examples, individuals consciously applied law to change the contexts in which persons with disabilities lived. But rights need not be specifically invoked, discussed, or even thought about; their generalized effects may nonetheless produce paradigmatic shifts in everyday thoughts and actions. The "constitutive" effect of law has been emphasized by a number of sociolegal scholars in recent years and is sometimes contrasted with more familiar "instrumental" effects (Sarat \& Kearns 1993). We acknowledge and reaffirm the constitutive role of law in everyday life, yet we do not see constitutive and instrumental effects as dichotomous alternatives (law is either constitutive or instrumental). Rather, in the autobiographical narratives of Sara Lane and Jill Golding, we can see a variety of ways-simultaneously instrumental and constitutive-in which rights intersect with culture and consciousness and play a part in the construction of everyday life.

Despite the sometimes subtle effects of law on everyday life, what is equally striking in all of our interviews is the absence of explicit references to or uses of the law. Sara Lane and Jill Golding are, in this sense, exceptional figures. For all their hesitations and doubts about introducing the ADA into their own employment settings, they are familiar with the law and more ready to speak of their rights than most of our other interviewees. And our interview sample no doubt brought us into contact with a group who tend to be more engaged and attentive to outside resources than many of their peers. For this very reason, we were all the more struck by the reluctance of most interviewees to characterize employment situations in terms of rights or, indeed, legal relationships of any kind. They typically assumed that employers could treat persons with disabilities as they pleased and that the appropriate response to unsupportive treatment was to work harder or leave. It was not just that our interviewees were often unaware of their rights; in many cases they actually believed that the provisions of the ADA exceeded the measure of social justice they were entitled in fairness to claim. The life stories of Sara Lane and Jill Golding suggest many reasons for their reluctance: personal privacy, concerns about job security, reluctance to work in a hostile environment, among others. Furthermore, as we have 
noted, an individual's orientation toward law tends to change and evolve over time. Individuals with disabilities may even adopt the antirights discourse we have cited earlier in this article. Some of our interviewees made explicit reference to this discourse and criticized the readiness of other minority groups to assert rights. At times, hostility to race-based claims of entitlement appeared to inhibit our interviewees from formulating disability-based claims of their own. Thus, the absence of law and the reluctance of individuals with disabilities to assert employment rights may be explained in different ways. Yet their reluctance is not fixed and unyielding, for it gives way on many occasions to a belief that the rejection of rights will lead to social isolation and dependence. ${ }^{13}$ In our conclusion, we argue that this ambivalence creates a dilemmas for holders of rights but also provides opportunities for creative resolution.

\section{Conclusion}

As the 20th century draws to a close, the debate over rights intensifies. One voice argues that rights provide the only sure way to include disempowered and marginalized persons in the mainstream of society and protect them against discrimination. Another voice asserts that rights disrupt social relationships, that they create oppositions rather than forge bonds, that they ultimately harm and even degrade those they are meant to help. The continual expansion of rights claims, from this perspective, threatens to undermine our sense of community.

Persons with disabilities are the beneficiaries of the most significant civil rights legislation of recent decades, perhaps the last such legislation we shall see in this political era. There is ample evidence documenting the discrimination, disempowerment, and oppression suffered by this social group; but how will new rights affect the lives and careers of persons with disabilities? Will the interplay between rights and day-to-day experience be constructive or destructive, significant or insignificant? If rights do become active in the lives of persons with disabilities, how will this occur? In what forms and through what mechanisms will the influence of these new rights be felt?

Our presentation of the life stories of Sara Lane and Jill Golding cannot provide definitive answers to these profoundly difficult questions. As we write, we continue to interview and reinterview others, searching with our interviewees for clues. Although the questions are not new, we have the unexpected sense that we are charting new terrain. Rarely have researchers attempted to discern the ways in which rights become active

13 Members of other minorities face similar dilemmas in asserting civil rights. Compare, for example, the response of a noted minority scholar to the critique of rights by the Critical Legal Studies movement (Williams 1987). 
throughout the course of a lifetime, linking early experiences and identity formation with perceptions and choices later in life. For persons with disabilities-and we suspect the same will be true for others to whom the law grants rights-it is essential to take this long view. Some of the most powerful understandings of inclusion and exclusion are presented early in their lives; yet early influences are not irrevocable. Over a lifetime, ideas and perceptions continually change. Rights can produce such changes, but the readiness to embrace rights is itself the product of earlier experiences and orientations.

Looking through a longer lens, we see with unusual clarity the shifting, changing role of rights in individual lives. We do not see two groups of individuals: those who mobilize their rights and those who fail (or refuse) to do so. Rather, we see individuals debating in their own minds how to respond to challenges and barriers they encounter in their day-to-day experiences. These internal debates at times remind us of the broader public debates over the role of rights in civil society and the constructive and destructive effects of rights assertion. Yet the internal debates of persons with disabilities have another dimension as well: They reflect the conflicting self-images these individuals have formed since childhood and the ambivalent assumptions they carry with them about their own capabilities and the nature of their relationships with others. The multiplicity of internal voices contributes to a variation in the telling of life stories from one occasion to the next. Such variations are reflected in the italicized commentaries we include in the two case studies presented in this article. We believe that these variations can be a source of creativity and strength-it is important for persons to draw on different ideas and images from their own past at different times, as they cope with new situations and new opportunities.

Sara Lane and Jill Golding approach the dilemma of rights and full participation in society with greater self-confidence and success than most. Yet they, like most of our interviewees, lack models or examples to follow. Their success is largely the product of their own creativity and perseverance. They engage in different strategies in different situations or at different times in their lives. They worry about the choices they make and the viewpoints they articulate to their bosses and co-workers. A bold act or statement is followed by concern that they have gone too far, yet silence or inaction carries its own risks. The interplay between rights and relationships defines the ambiguous space in their lives between what they need and what the law tells them they deserve.

Neither of these two relatively successful and confident women has invoked rights in a claim against their employer; both express great caution about the possibility that they might ever do so. A simple conclusion suggests itself: if Sara Lane and Jill 
Golding express strong reluctance about asserting rights under the ADA, then very few persons with disabilities can ever be expected to "mobilize" this landmark statute. Our research thus far provides some support for this conclusion. Most of our interviewees are even less likely than Sara and Jill to press a legal claim in the employment context. Yet we reject the conclusion that the ADA will have little effect on the lives and careers of people with disabilities. We believe that the life stories of individuals with disabilities would be quite different if not for the influence of the disability rights movement and the passage of civil rights legislation in the 1970s and 1990s.

As we listen to the life stories of Sara Lane, Jill Golding, and other individuals with disabilities, we recognize that rights may become active in many different ways other than the lodging of a formal claim: through the actions of employers and other third parties, through the introduction of rights into everyday conversations and confrontations, and through subtly pervasive changes in the framework of knowledge that helps to structure everyday life. Rights appear to play a role in society quite different from that assumed by either side in the public debates of recent years. The involvement of courts and lawyers in the mobilization of rights is rare and aberrational; yet the influence of rights on individual lives and on everyday life may nonetheless be very important.

Our research therefore challenges those who see a conflict between rights and a community of close relationships. Stories like Sara's and Jill's replace the old dichotomies and blur the coercion of law and the consensus of community. In our interviews, we encountered no occasions when individuals asserted their rights through the formal mechanisms of law; but we found many instances in which rights became active in other, less formal ways. We wonder whether those who bitterly denounce the expansion of rights in our society would change their views if they recognized that rights most often become active, not through litigation, but as part of the routines of everyday life. Would rights in this form seem to such critics to be less destructive and alienating? Would rights then seem more consistent with the goal of strengthening community? ${ }^{14}$

For Sara Lane and Jill Golding, the creation of new rights appears to be connected to positive developments in the shaping of individual identity and the strengthening of productive relationships with others. Rights rarely lead them to make claims

14 We recognize, of course, that some who denounce rights are less concerned about strengthening community than about retaining a status quo in which they enjoy privilege and power. Granting new rights can disrupt established hierarchies. As Weber (1968:667) observed: "Every right is thus a source of power of which even a hitherto entirely powerless person may become possessed. In this way he becomes the source of completely novel situations within the community." 
against. Rather, rights become another element in the internal dialogue, in the conversation within their own minds between the self that has been excluded and the self that has been included, between the part of their personality that seeks greater respect and fairness and the part that seeks an unexceptional, "normalized" identity in mainstream social settings. At times, rights prove capable of mediating this dialogue, suggesting new ways to mitigate the dilemma of difference and accommodate all the requirements of personhood. If rights can play a creative role in the transformation of internal dialogues, perhaps they can play such a role in the transformation of public dialogues as well. Rights need not oppose the desire for community; their effect on individual lives is not necessarily oppositional and alienating. Rather rights have the capacity to mediate the tension between divided understandings of those marked as different and to transform such understandings into new possibilities of inclusion. As rights become active in everyday life, they may finally be understood as a source of reconciliation rather than opposition.

\section{Epilogue}

After this article was accepted for publication in the Law $\mathcal{F}^{2}$ Society Review, we interviewed "Sara Lane" and "Jill Golding" again. The two women were eager to meet, and were willing to speak with us and with each other about the issues addressed in our final draft. Since we had last seen them, changes had occurred in both of their lives. Jill Golding had passed her licensing exam and was now a registered nurse. Sara Lane had undergone orthopedic surgery and anticipated a second operation in the near future. She observed that she had become more willing than in the past to request special leaves and accommodations and was increasingly inclined to present such requests in terms of her legal rights. She now viewed the individual rights framework as preferable to a strategy that relied on union intervention, for it had become clear to her that the union had no interest in advocating home work arrangements for any of its members. As discussion continued, Sara Lane and Jill Golding addressed each other and compared their current attitudes toward social change, rights, relationships, and the employment setting. We think it appropriate for them to have the last word.

SARA LANE: I don't think we're ready though to even sit down and say to ourselves "We did good. We got far." Because it always seems like there's another challenge that's on the horizon.

JILL GOLDING: Exactly, exactly.

SARA LANE: There's always something.

JILL GOLDING: We're always critical of ourselves. 
SARA LANE: And it's always the same frigging issues. They never change. . . . I sometimes feel like I'm talking to a wall except that I have this great woman supervisor who gets it and who puts her job on the line for me all the time. And I know she meets these incredible "Are you kidding?" kind of responses. So I think, bottom line, they feel sorry for me, and that's why they're doing what they're doing. It has nothing to do with my rights; they feel sorry for me. . . .

JILL GOLDING: I would tend to agree that a lot of people do feel sorry, but I think we have to say, "I don't care if you feel sorry for me or not. Is the end result what I want?". . . I might be the sorryass that got everything I wanted and everybody [pitied] me, but I don't have to accept the pity. I have to accept the just reward in the end. . . . So sometimes I think that it is hard to get what you want. But if the end result is to get what you want, it doesn't matter why you got it. Just be thankful that you got it. And make sure the reasons you wanted it were appropriate also. . . . Unfortunately you and I are the fighters. We're the front line in this battle; and as much as we're uncomfortable with it, it is still our duty as a human being to take care of that. To do it for ourselves, to do it for our family, to do it for the future generations. It doesn't mean it's going to be easy, and it certainly doesn't mean that we're going to get our rights met, but at least we can rest assured that we tried. . . .

SARA LANE: I think that our kids will have it better only because there's a better education process going on. And if passing the ADA boosted this education process, which I think it has-the mainstream media has done some good work since the ADA came out-that's more important to me than actually what the law will do. It's more how people's minds are changed, and that's education and that's what we're doing, unfortunately. . . . I think the only way that this will ever really come to fruition is in the workplace. I mean, where else in our lives are we peers as we are in the workplace? So it's critical for the education and for the whole implementation of the rights to be done on the job where people are equal. I mean, you're not going to do it in your church; you're not going to do it in the supermarket; it's got to be. And that's so unfortunate, because of the dinosaur that the American corporate world is, that that's the critical place. It wasn't that long ago when I was in college and I was told I couldn't be a teacher because a disabled woman could not handle a class of children. I mean, that's so bad to think about. Think about it: that's the only way to educate children, is to have a disabled teacher. You get them young, and you convince them right away.

JLL GOLDING: Certainly family education has to fall into place, too. I mean, old-fashioned thinkers that are parents, they have to, they can't sit there and stereotype. I don't know how to get that other than if they get it from their workplace. I think the workplace is the key-and then schools, because those are the two places that everybody falls into. But there's going to be a gap before everyone meets, and how long that gap 
is I don't know. But I think it's going to be shorter than we might have thought it would be years ago. . . . It's just unfortunate that they hold the key. They really do hold the key, you know.

$$
\text { * * * }
$$

JILL GOLDING: Rights or not, when it comes right down to it, if they fire you, yeah, you can sue, but what do you do in the year's time to support your family while you're fighting this lawsuit? It's great to have rights, but sometimes they aren't as helpful as we want them to be.

SARA LANE: It's not practical. It's just not practical for real life.

JILL GOLDING: It isn't. . . .

SARA LANE: [But] the symbolism of them I think is effective.

\section{References}

Black, Donald (1976) The Behavior of Law. New York: Academic Press.

Blanck, Peter David (1994) Communicating the Americans with Disabilities Act. Transcending Compliance: A Case Report on Sears, Roebuck and Co. Washington: The Annenberg Washington Program, Communications Policy Studies, Northwestern Univ.

Blau, Peter M., \& Otis Dudley Duncan (1967) The American Occupational Structure. New York: Wiley.

Bourdieu, Pierre (1977) Outline of a Theory of Practice. Cambridge: Cambridge Univ. Press.

Bruner, Jerome (1990) Acts of Meaning. Cambridge: Harvard Univ. Press.

Court, Patricia G., \& Linda Karr O'Connor (1992) "A Selected Bibliography on Employment and the Americans with Disabilities Act," 2 Cormell J. of Law $\mathcal{F}^{2}$ Public Policy 63.

Curran, Barbara A. (1977) The Legal Needs of the Public: The Final Report of a National Survey. Chicago: American Bar Foundation.

Elshtain, Jean Bethke (1995) Democracy on Trial. New York: Basic Books.

Ewick, Patricia, \& Susan S. Silbey (1992) "Conformity, Contestation, and Resistance: An Account of Legal Consciousness," 26 New England Law Rev. 731.

Feldblum, Chai R. (1991) "Employment Protections," 69 Milbank Q. 81 (Supps. 1/2).

Fine, Michelle, \& Adrienne Asch (1988) "Disability beyond Stigma: Social Interaction, Discrimination, and Activism," $44 \mathrm{~J}$. of Social Issues 3.

Frank, Gelya (1988) "Beyond Stigma: Visibility and Self-Empowerment of Persons with Congenital Limb Deficiencies," $44 \mathrm{~J}$. of Social Issues 95.

Friedman, Lawrence M. (1985) Total Justice. New York: Russell Sage Foundation.

Funk, Robert (1987) "Disability Rights: From Caste to Class in the Context of Civil Rights," in A. Gartner \& T. Joe, eds., Images of the Disabled: Disabling Images. New York: Praeger.

Galanter, Marc (1983) "Reading the Landscape of Disputes: What We Know and Don't Know (and Think We Know) about Our Allegedly Contentious and Litigious Society," 31 UCLA Law Rev. 4. 3. 
Gerber, David A. (1994) "Heroes and Misfits: The Troubled Social Reintegration of Disabled Veterans in 'The Best Years of Our Lives,' " 46 American $Q$. 545.

- (1995) "In Search of Al Schmid: War Hero, Blinded Veteran, Everyman," $29 \mathrm{~J}$. of American Studies 1.

Glendon, Mary Ann (1991) Rights Talk: The Impoverishment of Political Discourse. New York: Free Press.

Gliedman, John, \& William Roth (1980) The Unexpected Minority: Handicapped Children in America. New York: Harcourt, Brace \& Jovanovich.

Goffman, Erving (1963) Stigma. Englewood Cliffs, NJ: Prentice Hall.

Gooding, Caroline (1994) Disabling Laws, Enabling Acts: Disability Rights in Britain and America. London: Pluto Press.

Gostin, Lawrence D., \& Henry A. Beyer (1993) Implementing the Americans with Disabilities Act: Rights and Responsibilities of All Americans. Baltimore: Paul $\mathrm{H}$. Brookes Publishing Co.

Graham, Sandra (1991) "A Review of Attribution Theory in Achievement Contexts," 3 Educational Psychology Rev. 5.

Greenhouse, Carol J., Barbara Yngvesson, \& David M. Engel (1994) Law and Community in Three American Towns. Ithaca, NY: Cornell Univ. Press.

Groce, Nora Ellen (1985) Everyone Here Spoke Sign Language. Cambridge: Harvard Univ. Press.

Handler, Joel (1987-88) "The Transformation of Aid to Families with Dependent Children: The Family Support Act in Historical Context," 16 New York Univ. Rev. of Law E Social Change 457.

Harrington, Christine B., \& Barbara Yngvesson (1990) "Interpretive Sociolegal Research," 15 Law Eo Social Inquiry 135.

Haskell, Thomas L. (1987) "The Curious Persistence of Rights Talk in 'The Age of Interpretation," " $74 \mathrm{~J}$. of American History 984.

Laumann, Edward 0., ed. (1970) Social Stratification: Research and Theory for the 1970s. Indianapolis: Bobbs-Merrill.

Livneh, Hannoch (1983) "Death Anxiety and Attitudes towards Disabled Persons," 53 Psychological Reports 359.

Makas, Elaine (1988) "Positive Attitudes toward Disabled People: Disabled and Nondisabled Persons' Perspectives," $44 \mathrm{~J}$. of Social Issues 49.

Mayhew, Leon, \& Albert J. Reiss, Jr. (1969) "The Social Organization of Legal Contacts," 34 American Sociological Rev. 309.

McCann, Michael W. (1994) Rights at Work: Pay Equity Reform and the Politics of Legal Mobilization. Chicago: Univ. of Chicago Press.

Merry, Sally Engle (1990) Getting Justice and Getting Even: Legal Consciousness among Working-Class Americans. Chicago: Univ. of Chicago Press.

Miller, Richard E., \& Austin Sarat (1980-81) "Grievances, Claims, and Disputes: Assessing the Adversary Culture," 15 Law E Society Rev. 525.

Milner, Neal (1989) "The Denigration of Rights and the Persistence of Rights Talk: A Cultural Portrait," 14 Law E Social.Inquiry 631.

Minow, Martha (1990) Making All the Difference: Inclusion, Exclusion, and American Law. Ithaca, NY: Cornell Univ. Press.

Morin, Elizabeth Clark (1990) "Americans with Disabilities Act of 1990: Social Integration through Employment," 40 Catholic University Law Rev. 189.

Murphy, Robert F. (1987) The Body Silent. New York: Henry Holt.

Newman, Katherine (1988) Falling from Grace: The Experience of Downward Mobility in the American Middle Class. New York: Free Press.

Oliver, Michael (1990) The Politics of Disablement: A Sociological Approachment. New York: St. Martins Press.

Sarat, Austin, \& Thomas R. Kearns (1993) "Beyond the Great Divide: Forms of Legal Scholarship and Everyday Life," in A. Sarat \&c T. R. Kearns, eds., Law in Everyday Life. Ann Arbor: Univ. of Michigan Press. 
Scheer, Jessica (1984) “'They Act Like It's Contagious': A Study of Mobility Impairment in a New York City Neighborhood," in S. C. Hey, G. Kiger, \& J. Seidel, eds., Social Aspects of Chronic Illness: Impairment and Disability. Salem, OR: Willamette Univ. Press.

Trubek, David M., Austin Sarat, William L. F. Felstiner, Herbert M. Kritzer, \& Joel B. Grossman (1983) "The Costs of Ordinary Litigation," 31 UCLA Law Rev. 72.

Tucker, Bonnie P. (1989) "The American with Disabilities Act: An Overview," 1989 Univ. of Illinois Law Rev. 923.

(1992) "The ADA, Interpreting the Title I Regulation: The Hard Cases," 2 Cornell J. of Law E Public Policy 1.

Tushnet, Mark (1984) "An Essay on Rights," 62 Texas Law Rev. 1363.

Weber, Max (1968) Economy and Society: An Outline of Interpretive Sociology. 3 vols. Guenther Roth and Claus Wittich, eds. Ephraim Fischoff et. al., trans. New York: Bedminster Press.

West, Jane (1993) "The Evolution of Disability Rights," in Gostin \& Beyer 1993. ed. (1991) "The Americans with Disabilities Act: From Policy to Practice," 69 Milbank $Q .3$ (Supps. 1/2).

Williams, Patricia (1987) "Alchemical Notes: Reconstructing Ideals from Deconstructed Rights," 22 Harvard Civil Rights-Civil Liberties Law Rev. 401.

Wright, Beatrice A. (1983) Physical Disability-A Psychosocial Approach. 2d ed. New York: Harper \& Row.

Yngvesson, Barbara (1988) "Making Law at the Doorway: The Clerk, the Court, and the Construction of Community in a New England Town" 22 Law $\mathcal{E}^{\circ}$ Society Rev. 409.

- (1993) Virtuous Citizens, Disruptive Subjects: Order and Complaint in a New England Court. New York: Routledge.

Zola, Irving K. (1993) "The Sleeping Giant in Our Midst: Redefining 'Persons with Disabilities," " in Gostin \&c Beyer 1993.

\section{Statutes}

Rehabilitation Act of 1973, 29 U.S.C. § 794 (1988).

Education for All Handicapped Children Act of 1975, Pub. L. No. 94-142, 89 Stat. 773 (1975).

Individuals with Disabilities Education Act, 20 U.S.C. $\$ \S 1400-1485$ (Supp. 11 1990).

Americans with Disabilities Act of 1990, 42 U.S.C. $\$ \S 12101-12213$ (Supp. IV 1992). 